\title{
El ciclo hidro-social de los ríos urbanos: Transformaciones al paisaje hídrico en San Luis Potosí, México
}

\author{
The Hydro-social Cycle of Urban Rivers: Waterscape Transformations to the Hydro \\ Landscape of San Luis Potosí, México
}

\section{Lourdes Marcela López-Mares ${ }^{1}$, Juan Manuel Lozano de Poo ${ }^{2}$, Fernando Torre- Silva Josué Rodríguez-Santiago ${ }^{4}$ y Julio Alberto López-Fraga ${ }^{5}$}

[Recibido: 15 febrero 2018, Aceptado: 22 de junio 2018, Corregido: 20 de julio 2018, Publicado: 1 de enero 2019]

\begin{abstract}
Resumen
En el presente trabajo de corte exploratorio analizamos las transformaciones de los tres ríos urbanos principales de la Zona Metropolitana de San Luis Potosí: el río Santiago, el río Españita y el río Paisanos. Desde un enfoque hidro-social, el análisis aborda las transformaciones físicas de los ríos en relación con el crecimiento urbano y con los cambios en la interacción y el significado que la sociedad otorga al recurso hídrico. Para llevarlo a cabo se realizó un mapeo interpretativo en el que se sobrepusieron capas con información histórica, sociodemográfica, geográfica e hidrológica. Además, se administraron entrevistas con informantes clave y se consultaron fuentes secundarias. Estos métodos permitieron reconstruir las transformaciones de los ríos desde las lógicas impresas, los usos del espacio y del agua y los tipos de agua que derivan de la relación dialéctica entre naturaleza y sociedad. Los hallazgos principales del trabajo indican que todos los cauces han sido modificados en beneficio del crecimiento urbano. Además, el vínculo social con los ríos como elementos naturales y fuentes de vida se ha roto; actualmente los cauces son percibidos como fuentes de contaminación e inseguridad, más útiles como elementos urbanos que naturales. Este cambio de percepción explica por qué los cauces se encuentran actualmente fragmentados de forma física y simbólica.
\end{abstract}

Palabras clave: Ciclo hidro-social; ciudades; paisaje hídrico; ríos urbanos.

\begin{abstract}
This exploratory study analyses the transformations of the three main urban rivers within the Metropolitan Area of San Luis Potosí: Rio Santiago, Rio Españita and Rio Paisanos. From a hydro-social perspective, the analysis focuses on the physical transformations of the rivers and their relationship with urban sprawl and on the meaning and interaction changes between society and the hydric resource. For the study, was conducted an interpretive mapping

1 Académica de la Facultad del Hábitat de la Universidad Autónoma de San Luis Potosí, México marcela.lopez@uaslp.mx

2 Académico de la Facultad del Hábitat de la Universidad Autónoma de San Luis Potosí, México. juan.depoo@uaslp.mx

3 Director del Instituto Municipal de Planeación de San Luis Potosí, México. fernandotorre_@hotmail.com

4 Pasante de Arquitectura de la Facultad del Hábitat de la Universidad Autónoma de San Luis Potosí, México. robejosuerodriguez@gmail.com

5 Estudiante de licenciatura de Diseño Urbano y del Paisaje de la Facultad del Hábitat de la Universidad Autónoma de San Luis Potosí, México. oncemindless@hotmail.com
\end{abstract}

(c) (9)(5)




\section{Revista de CIENCIAS AMBIENTALES Tropical Journal of Environmental Sciences}

Revista de Ciencias Ambientales (Trop J Environ Sci). EISSN: 2215-3896.

(Enero-Junio, 2019) . Vol 53(1): 45-69.

D0l: http://dx.doi.org/10.15359/rca.53-1.3

Open Access: www.revistas.una.ac.cr/ambientales EMAlL: revista.ambientales@una.ac.cr

López-Mares L. M., Lozano de Poo J. M., Torre-Silva F., Rodríguez-Santiago J. y López-Fraga J. A.

exercise overlapping layers with historical, socio-demographic, geographic and hydrological information. Additionally, interviews were administered to key informants and secondary sources were reviewed. These methods allowed to re-construct the rivers' transformations to understand the logics employed, resulting space and water uses and the types of water derived from the dialectic interaction nature-society. The major findings of the research indicate that all three rivers have been transformed to benefit urban growth. Furthermore, the social bond with rivers as natural elements and sources of life has been broken; nowadays, riverbeds are perceived as sources of pollution and insecurity, more useful as urban elements than as natural landscape components. This perception shift explains the reason why river courses are currently fragmented in a physical and symbolical manner.

Keywords: cities; hydro-social cycle; urban rivers; waterscape.

\section{Introducción}

\begin{abstract}
“Qué se hicieron, diría una voz enérgica, aquellos ríos caudalosos y permanentes que fertilizaban el hermoso valle de San Luis Potosí, y que, derramando sobre sus terrenos la belleza y la abundancia, aún mucho antes de la conquista de los españoles, daban pingüe sustento y envidiable felicidad a sus pacíficos y laboriosos habitadores?"
\end{abstract}

Arriaga, Balbontín, Ávila y Escontría (1843, en Padrón, 2014, p. 2)

El recurso hídrico es fundamental para la vida de las ciudades; sin embargo, la relación entre el crecimiento urbano, el uso y la gestión sustentable del recurso es una de constante tensión. En la Zona Metropolitana de San Luis Potosí (ZMSLP), los mantos acuíferos abastecen más del $90 \%$ del agua necesaria para mantener las actividades económicas y domésticas urbanas. No obstante, estos mantos se encuentran sobreexplotados, situación que ha forzado a la ciudad a incrementar su huella hídrica teniendo que importar el recurso de fuentes cada vez más alejadas. Lo anterior ha sucedido también con las fuentes superficiales de agua como ríos, lagunas de inundación y humedales que formaban parte del sistema hídrico de la ciudad. San Luis Potosí fue fundada precisamente por la existencia de fuentes superficiales de agua necesarias para el beneficio de la extracción de plata del Cerro de San Pedro, así como para la actividad ganadera y agrícola necesaria para mantener a la población. Sin embargo, tanto las fuentes superficiales como los mantos acuíferos han sido gradualmente desecados - en favor del crecimiento urbano-desde un esquema de gestión de agua lineal en el que el recurso se consume, desecha, canaliza y, finalmente, se expulsa fuera de la ZMSLP lo más rápido posible.

Este trabajo exploratorio sobre el uso de los cauces en la ZMSLP, da cuenta de cómo los cambios más importantes en el tipo de agua que conducen y en su morfología, se encuentran

\begin{tabular}{|c|c|c|}
\hline 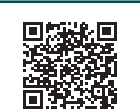 & (c) (i) (5) (2) & 46 \\
\hline
\end{tabular}


directamente relacionados con tres factores: el significado social que se les atribuye, el crecimiento urbano y el ciclo del agua. La relación entre estos factores ha sido abordada desde diferentes perspectivas hidro-políticas que analizan: 1) diferentes formas de organización social y de gestión del agua (sociedades hídricas); 2) el rol de las infraestructuras hídricas y esquemas institucionales en cambios socio-ecológicos (enfoque socio-material); 3) las racionalidades y prácticas atomizadas de poder para controlar el recurso (gubernamentalidad de Foucault); 4) avances tecnológicos relacionados con el agua y su empleo para avanzar objetivos políticos (tecnopolítica) y, finalmente; 5) la relación dialéctica entre el agua y la sociedad, es decir, la forma en la cual el agua produce constelaciones sociales distintivas y en la que la sociedad produce 'tipos de agua' específicos (ciclo hidro-social) (Linton y Budds, 2014; Mehta y Karpouzoglou, 2015; Rogers y Crow-Miller, 2017; Shannon, 2019).

En este trabajo nos adherimos a este último enfoque, desde el cual partimos para identificar momentos de intersección en la relación dialéctica naturaleza-sociedad-entorno urbano. Para ello, dividimos el trabajo en cinco partes. La primera presenta un marco de referencia y antecedentes de la ZMSLP con el fin de contextualizar empírica y teóricamente los cauces estudiados. Después presentamos un apartado metodológico, seguido de una descripción de cada cauce. Posteriormente, analizamos cada uno de los enfoques estudiados desde un cauce en específico y concluimos con reflexiones del trabajo, recomendaciones e implicaciones de la investigación.

\section{Marco de referencia}

Vivimos en un mundo cada vez más urbano, en donde incluso los territorios conservados "al natural" son sometidos a la lógica urbana dominante (Lefebvre, Kofman y Lebas, 1996). Es decir, estos se estructuran, comunican y sirven a un contexto urbano en redes, cada vez más globalizado, que se caracteriza por la explotación desregulada de recursos y el incremento de las fronteras de su huella ecológica más allá de sus límites y regulaciones. Si el impacto ecológico de este fenómeno es profundo al exterior de nuestros sistemas urbanos, al interior lo es aún más. Esta tendencia se presenta en un gran número de ciudades latinoamericanas, las cuales han experimentado un crecimiento urbano acelerado en las últimas 5 décadas. La ZMSLP, por ejemplo, multiplicó su población por cuatro aproximadamente entre los años 1960 y 2000, y su extensión por ocho en el mismo período (Contreras y Galindo, 2008; INEGI, 2011). Este crecimiento expansivo va de la mano con la sobreexplotación de los mantos acuíferos, la contaminación del aire y la deforestación.

Sometidos a la lógica urbana, los ríos que se encuentran al interior de la ZMSLP se han visto profundamente afectados por el crecimiento exponencial de la ciudad. Si nos remontamos a su fundación, las fuentes de agua superficial fueron clave para sostener la vida económica y la subsistencia de sociedades hídricas nacientes (Linton y Budds, 2014). Sin embargo, con el paso del tiempo, las aguas superficiales fueron captadas y canalizadas para abastecer a la población, desde un paradigma modernizador (Swyngedouw, 1999), basado en la construcción de grandes

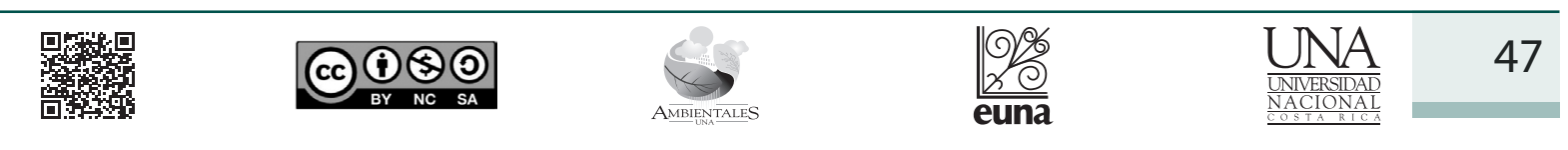


infraestructuras hídricas como presas y en el control centralizado del recurso. Con este 'viejo' paradigma, el agua es percibida como un recurso explotable y su gestión se resuelve mediante la ingeniería hídrica (Linton y Budds, 2014). En San Luis Potosí, la construcción de presas comienza en 1828, de forma que para 1960, el $60 \%$ del agua para consumo urbano provenía de estas fuentes. Posteriormente, la perforación de pozos permitió la extracción de agua del acuífero profundo, el cual abastece actualmente más del $90 \%$ del agua que se consume en la ZMSLP (Contreras y Galindo, 2008).

La reducción en el uso de las aguas superficiales está en relación directa con las transformaciones que han sufrido los ríos urbanos y la percepción social que se tiene de estos mismos, desde fuentes de vida hasta fuentes de riesgo y contaminación. En las últimas décadas, los cauces de los ríos se han desecado y sus bordes han sido rebasados por un crecimiento urbano que les da la espalda, y les otorga un uso de traspatio y repositorio de desechos. Estos problemas, aunados a la falta de mantenimiento, han promovido una percepción social negativa de los ríos. En un estudio realizado en el río Magdalena, en la Ciudad de México, Perló y Zamora (2017) analizaron la perspectiva ambiental de una muestra de personas que habita en la microcuenca del río. En él, encontraron que el río es percibido como un patrimonio medioambiental, pero las palabras que utilizan para caracterizarlo son mayoritariamente negativas y relacionadas con su contaminación. La percepción social de los ríos y el acelerado crecimiento urbano han justificado intervenciones mediante las cuales los ríos han sido desviados, canalizados y pavimentados, se niega, así, su presencia en el entorno urbano y se transforma su naturaleza. Este fenómeno responde a una lógica desarrollista que busca someter a la naturaleza y hacerla producir con criterios expansionistas. En la ciudad de México, por ejemplo, $83 \mathrm{~km}$ de ríos han sido 'borrados' del mapa (González et al., 2010, p. 34), en Guadalajara, cerca del 88 \% de los ríos urbanos han sido entubados (El Informador, 2010). Así mismo, en las ciudades de Aguascalientes, Morelia y Puebla, entre otras, se han llevado a cabo intervenciones similares. En San Luis Potosí, la pavimentación de los ríos Santiago y Españita comenzó en 1985, y a la fecha se siguen extendiendo dichas prácticas.

Al pavimentar los ríos se impermeabiliza una superficie que de manera natural infiltra agua al subsuelo, también se aceleran las escorrentías que provocan inundaciones aguas abajo, se contaminan los escurrimientos, se destruyen ecosistemas riparios y, por lo tanto, se reduce la biodiversidad (Dallman, Piechota \& Green, 1999). Finalmente, este tipo de transformaciones subestima el potencial de los ríos como fuentes de agua limpia, elementos paisajísticos en el entorno urbano, ejes de equipamiento e infraestructura verde y elementos de identidad e historia para quienes habitan las ciudades.

Las transformaciones sufridas por los ríos urbanos son manifestaciones de la producción social del espacio (Lefebvre, Kofman, \& Lebas, 1996), mediante las cuales se busca gestionar, domesticar y usar a la naturaleza en favor del crecimiento urbano y económico. Transformaciones que, por tanto, responden a discursos y contextos políticos, sociales y económicos específicos, cuya conjunción ejerce presión sobre los cauces urbanos: "Difícilmente alguna cuenca fluvial,

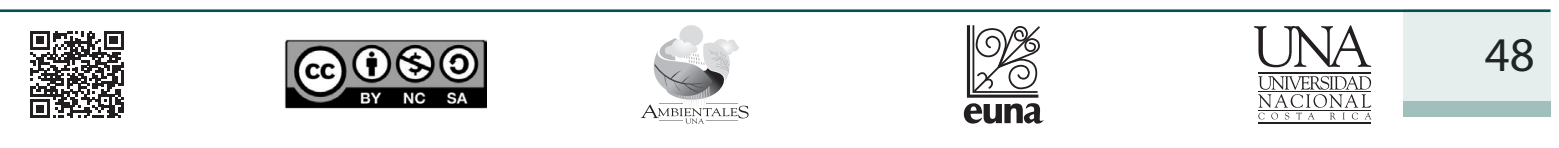




\section{Revista de CIENCIAS AMBIENTALES Tropical Journal of Environmental Sciences}

Revista de Ciencias Ambientales (Trop J Environ Sci). EISSN: 2215-3896.

(Enero-Junio, 2019) . Vol 53(1): 45-69.

D0l: http://dx.doi.org/10.15359/rca.53-1.3

Open Access: www.revistas.una.ac.cr/ambientales EMAIL: revista.ambientales@una.ac.cr López-Mares L. M., Lozano de Poo J. M., Torre-Silva F., Rodríguez-Santiago J. y López-Fraga J. A.

ciclo hidrológico, o flujo de agua no ha sido sujeto de alguna forma de intervención o uso" (Swyngedouw, 1999, p. 444), bajo procesos que Smith denomina como "la producción de la naturaleza" (Swyngedouw, 1999, p. 445).

Adicionalmente, la producción social de la naturaleza, vista desde el enfoque del ciclo hidro-social, no solo implica la domesticación de lo natural para fines sociales, sino también la reconfiguración social desde lo natural en una relación dialéctica. Según Linton y Budds (2014, p. 170), el ciclo hidro-social es un "...proceso en el cual agua y sociedad se hacen y rehacen mutuamente en el espacio y el tiempo.... Este enfoque se contrapone al del ciclo hidrológico que entiende al recurso como apolítico, reduciéndolo a su dimensión material. El ciclo hidro-social aborda al agua como parte $-\mathrm{y}$ no como telón de fondo- de las relaciones sociales y de poder, y como moldeadora de discursos, historias y subjetividades (Damonte, 2015). En resumen, este enfoque nos permite entender cómo la gestión del agua afecta tanto a las organizaciones como a los constructos sociales, y cómo diversas relaciones sociales producen diferentes tipos de agua (p.ej., limpia aguas arriba, contaminada aguas abajo) en ciclos y procesos iterativos.

Lo 'urbano', como un tercer ingrediente en la dialéctica mencionada anteriormente, es también producido por procesos sociales y naturales $\mathrm{y}$, a su vez, productor de estos:

Las condiciones geográficas...son reconstruidas como resultado de un proceso de producción en el cual tanto la naturaleza como la sociedad se fusionan de manera que se vuelven inseparables, produciendo un cuasi objeto híbrido e inquieto en el que prácticas materiales, simbólicas y de representación se encuentran amalgamadas. (Swyngedouw, 1999, p. 461)

El reto que enfrentamos, entonces, es el de analizar esta amalgama para entender los híbridos generados a partir de la producción social de lo natural y lo urbano en conjunto. En línea con Swyngedouw (1999, p. 447), entendemos la hibridación como un "... proceso de producción, de devenir, de transgresión perpetua”, del cual derivan 'cuasi objetos' o 'cyborgs', entes mixtos, fusionados y sin límites rígidos, pero de numerosas contradicciones: "...estos objetos/sujetos, parte sociales, parte naturales y a la vez profundamente históricos, y por lo tanto producidos, son intermediarios que encarnan y expresan a la naturaleza y a la sociedad, tejiendo redes de espacios liminales infinitos". Los espacios liminales o intersticiales que se generan forman parte de un proceso que, como el paso del agua, se encuentran en flujo constante.

En este trabajo pretendemos abordar este flujo y cambio constante mediante un enfoque de procesos. Buscamos leer la narrativa de los paisajes hídricos de la ZMSLP, entendida desde los espacios liminales o cuasi-objetos, derivados de la relación dialéctica entre lo social, natural y urbano. Para ello, nos servimos del concepto de paisaje hídrico para leer en tiempo presente estos cambios, como "imágenes de un tiempo específico en la continua reformulación entre sociedad y agua" (Rogers y Crow-Miller, 2017, p. 3). Un paisaje hídrico (waterscape) es el resultado de la acción de procesos sociales y políticos en el entorno hídrico natural. Estos procesos develan relaciones de poder, producción de símbolos, imágenes y discursos que, una vez impresos

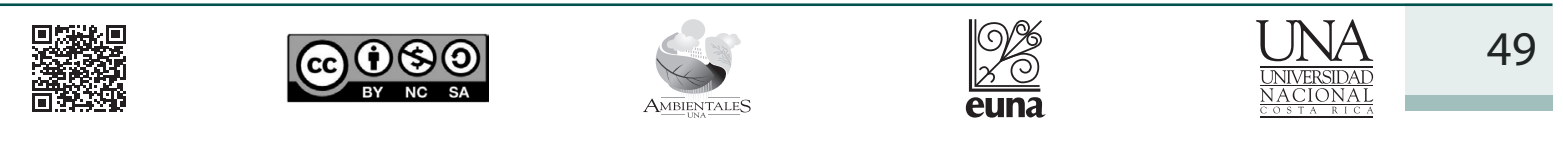




\section{Revista de CIENCIAS AMBIENTALES Tropical Journal of Environmental Sciences}

Revista de Ciencias Ambientales (Trop J Environ Sci). EISSN: 2215-3896. (Enero-Junio, 2019) . Vol 53(1): 45-69. D0l: http://dx.doi.org/10.15359/rca.53-1.3 Open Access: www.revistas.una.ac.cr/ambientales EMAlL: revista.ambientales@una.ac.c López-Mares L. M., Lozano de Poo J. M., Torre-Silva F., Rodríguez-Santiago J. y López-Fraga J. A.

en el paisaje, contribuyen a formar nuevas identidades y a justificar las externalidades generadas (Mele, 2000; Swyngedouw, 1999).

\section{Metodología}

Este trabajo se enfoca en las múltiples narrativas generadas a partir de la relación dialéctica entre las dimensiones social, natural y urbana, a lo largo del proceso de su mutua transformación. Por lo tanto, pretendemos trascender la tricotomía de la cual partimos como herramienta heurística para concentrarnos en la hibridación de sus relaciones internas (Linton y Budds, 2014). Para ello nos enfocaremos en las lógicas que han producido estos paisajes, en sus usos sociales y urbanos, en sus transformaciones físicas y de significado, y en los tipos de agua que derivan de la compleja relación sociedad-naturaleza.

Para el estudio seleccionamos tres casos de la ZMSLP: el río Santiago, el río Españita y el río Paisanos, que además de ser los cauces más grandes, dan cuenta de los paradigmas preponderantes en relación con los paisajes hídricos urbanos: tramos de los dos primeros fueron soterrados y su cauce pavimentado, y el tercero es actualmente un repositorio de desechos urbanos y agrícolas.

Para estudiarlos, realizamos un mapeo interpretativo (Interpretive mapping, Rojas, De Meulder y Shannon, 2015), a través del cual superpusimos capas de información histórica, geográfica y social para entender los cambios en las relaciones sociedad-naturaleza-urbanización a través del tiempo. En el Cuadro 1 se muestran los métodos de recolección empleados, el tipo de información obtenida mediante cada uno, la fuente y cómo se analizó.

Cuadro 1. Métodos de recolección y análisis de datos

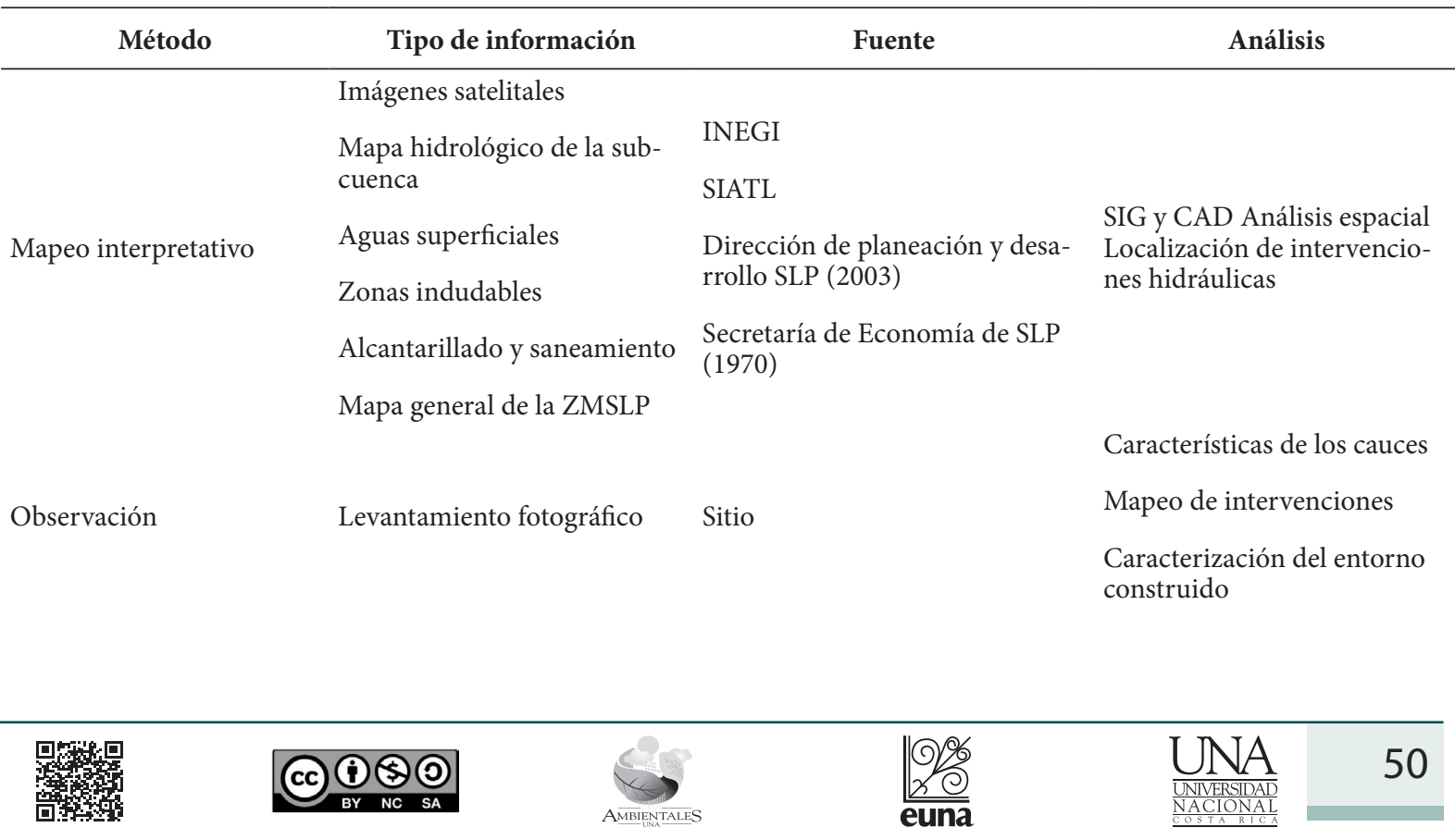




\section{Revista de CIENCIAS AMBIENTALES Tropical Journal of Environmental Sciences}

Revista de Ciencias Ambientales (Trop J Environ Sci). EISSN: 2215-3896.

(Enero-Junio, 2019) . Vol 53(1): 45-69.

DOl: http://dx.doi.org/10.15359/rca.53-1.3

Open Access: www.revistas.una.ac.cr/ambientales EMAlL: revista.ambientales@una.ac.cr López-Mares L. M., Lozano de Poo J. M., Torre-Silva F., Rodríguez-Santiago J. y López-Fraga J. A.

\begin{tabular}{|c|c|c|c|}
\hline Método & Tipo de información & Fuente & Análisis \\
\hline \multirow{2}{*}{ Entrevistas } & $\begin{array}{l}\text { Información de primera } \\
\text { mano }\end{array}$ & $\begin{array}{l}\text { Informantes clave de INTERA- } \\
\text { PAS }\end{array}$ & \multirow{2}{*}{$\begin{array}{l}\text { Análisis de contenido (adjeti- } \\
\text { vos que describen el río) }\end{array}$} \\
\hline & \multirow[t]{2}{*}{$\begin{array}{l}\text { Percepciones, valores y acti- } \\
\text { tudes }\end{array}$} & Residentes de la subcuenca & \\
\hline \multirow{5}{*}{ Investigación documental } & & Fuentes secundarias como: & \multirow{5}{*}{$\begin{array}{l}\text { Localización de lógicas y } \\
\text { discursos en las transforma- } \\
\text { ciones hidráulicas }\end{array}$} \\
\hline & \multirow{4}{*}{$\begin{array}{l}\text { Histórica } \\
\text { Hemerográfica }\end{array}$} & Tesis & \\
\hline & & Periódicos locales & \\
\hline & & Revistas & \\
\hline & & $\begin{array}{l}\text { Reportes técnicos sobre la sub- } \\
\text { cuenca }\end{array}$ & \\
\hline
\end{tabular}

El mapeo interpretativo partió de la compilación de imágenes satelitales e información cartográfica del INEGI (2017). Esto nos permitió obtener las magnitudes y extensiones aproximadas de los cauces y definir un radio inmediato de influencia de los ríos para analizar colonias aledañas, equipamiento y población directamente afectada. Para ello definimos un área de influencia radial (buffer) con centro en la inmediación del cauce a $400 \mathrm{~m}$, una distancia considerada como caminable.

Esta información fue combinada con mapas históricos para identificar y visualizar las trasformaciones de los 3 ríos. Caracterizamos estas transformaciones de acuerdo con las intervenciones principales: pavimentar, entubar, captar, desviar, expulsar, colectar, canalizar y desechar (ver Figura 1). A partir de estas intervenciones identificamos paisajes hídricos resultantes que, lejos de ser homogéneos, se refieren a las lógicas predominantes detrás de la producción.

En paralelo, realizamos visitas a los ríos en diferentes temporadas del año para observación, mapeo y registro fotográfico, con el fin de entender y ubicar geográficamente sus usos, transformaciones y problemáticas. Además, llevamos a cabo entrevistas no estructuradas con informantes clave del organismo municipal de gestión del agua (INTERAPAS) y con residentes del río Paisanos ( $n=9)$, con el propósito de comprender la distribución de los ríos y la forma en la que fluyen las corrientes en la ZMSLP. Las personas entrevistadas fueron seleccionadas en función de su disponibilidad y asistencia a talleres de diseño participativo que organizamos junto con un colectivo ciudadano. Sus respuestas nos ayudaron a entender la manera en cómo perciben al río, los problemas que identifican y las soluciones que proponen. Finalmente, la investigación documental se orientó hacia una búsqueda de datos que nos permitieran comprender la historia, el uso y significado otorgado a los ríos, en fuentes secundarias como trabajos de tesis, revistas de difusión como La Corriente y en notas periodísticas de los diarios de mayor circulación desde 1950, ya que a partir de esta década se puso en la agenda pública la transformación del río Santiago en vialidad.

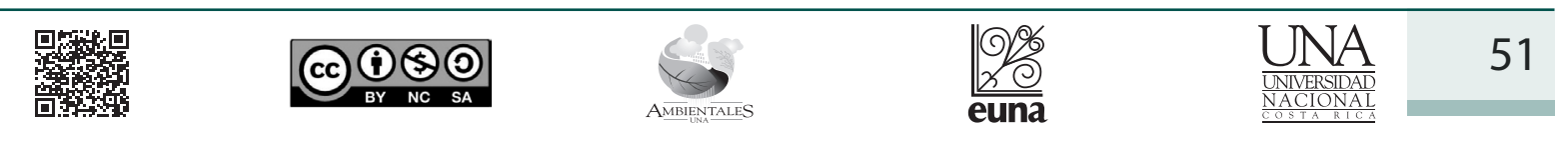




\section{Revista de
CIENCIAS AMBIENTALES Tropical Journal of Environmental Sciences}

Revista de Ciencias Ambientales (Trop J Environ Sci). EISSN: 2215-3896. (Enero-Junio, 2019) . Vol 53(1): 45-69. DOl: http://dx.doi.org/10.15359/rca.53-1.3 Open Access: www.revistas.una.ac.cr/ambientales EMAlL: revista.ambientales@una.ac.cr López-Mares L. M., Lozano de Poo J. M., Torre-Silva F., Rodríguez-Santiago J. y López-Fraga J. A.

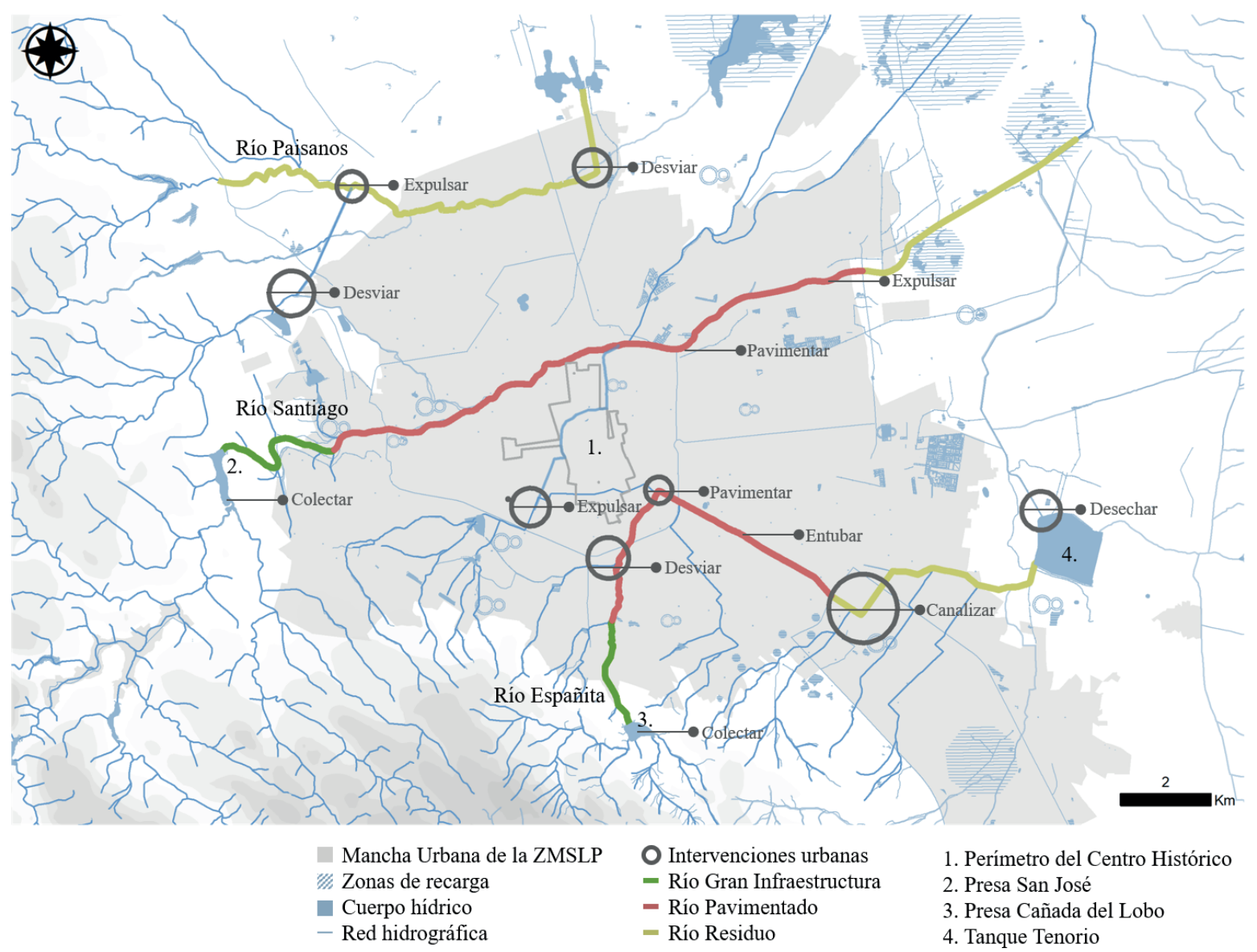

Figura 1. Ubicación de los casos de estudio. Elaborado con base en INEGI (2017) y SIATL (2018).

\section{Casos}

"No recuerdo que haya llegado un día de San Juan sin que en los tres ríos, España o del Santuario, el de Santiago y el del Paisano, no corriera agua con más o menos abundancia."

Periódico El Estandarte (1908) en La Corriente (2016)

En esta sección describimos brevemente los ríos estudiados. En cada caso identificamos, según sus características principales, componentes y usos del espacio, tramos que clasificamos en unidades de paisaje 'hídrico', que si bien no son totalmente homogéneas, nos ayudan a
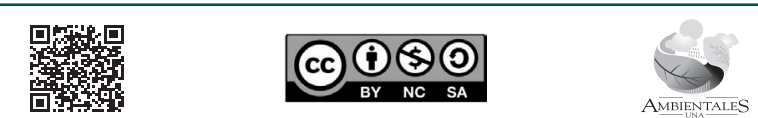


\section{Revista de CIENCIAS AMBIENTALES Tropical Journal of Environmental Sciences}

Revista de Ciencias Ambientales (Trop J Environ Sci). EISSN: 2215-3896.

(Enero-Junio, 2019) . Vol 53(1): 45-69.

D0l: http://dx.doi.org/10.15359/rca.53-1.3

Open Access: www.revistas.una.ac.cr/ambientales EMAlL: revista.ambientales@una.ac.cr López-Mares L. M., Lozano de Poo J. M., Torre-Silva F., Rodríguez-Santiago J. y López-Fraga J. A.

identificar patrones detrás de la lógica de las transformaciones de los ríos (Muñoz, 2004). Para esta clasificación integramos también criterios directamente relacionados con el agua, como los usos que socialmente se le atribuyen y los tipos de agua que resultan de las transformaciones en los ríos. Sintetizamos esta información en cuadros acompañados por mapas interpretativos que indican, geográficamente, momentos clave en la narrativa de cada río.

Los tres cauces principales de la ZMSLP pertenecen a la región hidrológica El Salado, una de las vertientes interiores más importantes en extensión de México. Según la Comisión Nacional del Agua, las corrientes de esta región “...tienen régimen intermitente, no tienen el carácter de propiedad nacional, y no se encuentran instrumentadas hidrométricamente, es decir, no se cuenta con información de gastos sobre las mismas" (CONAGUA, 2009). El $54.2 \%$ de esta región se encuentra en el Estado de San Luis Potosí y se caracteriza por contener una serie de cuencas cerradas sin grandes corrientes superficiales. Específicamente, los ríos estudiados se ubican en la cuenca Presa San José-Los Pilares, enclavada en una topografía serrana con un gran número de corrientes superficiales intermitentes (INEGI, 2010). El colector principal de esta cuenca es el río Santiago, cuyos escurrimientos desembocan en lagunas de inundación e infiltración $40 \mathrm{~km}$ al este de la ZMSLP (Contreras y Galindo, 2008).

\subsection{Río Santiago}

El área en donde se encuentra la cuidad de San Luis Potosí contaba con diversas fuentes de agua superficial, entre ellas tres ríos de temporal, numerosas acequias y lagunas de infiltración e inundación (Salazar, 2010). El río Santiago fue un elemento clave para la fundación de la ciudad en 1592. La extracción minera en Cerro de San Pedro, a 22 km de la actual capital, obligó a los grupos colonizadores españoles a buscar un sitio cercano con disponibilidad de agua para uso humano y de beneficio de los metales (Urquiola, 2004). Este río, ubicado a las afueras de la capital potosina, era el más importante de estos afluentes y permitió el aprovechamiento hídrico para el riego de huertas en las poblaciones de Santiago, Tlaxcala y parte de Tequisquiapan (Hernández-Fuentes, 2010).

El río tiene una extensión aproximada de $70 \mathrm{~km}$, desde el nacimiento de uno de sus afluentes en las inmediaciones de la sierra de San Miguelito, hasta su desembocadura en las lagunas de la Tinaja, al noreste de la ZMSLP (INEGI, 2017). El Cuadro 2 nos muestra la extensión de cada unidad de paisaje, altitud y ancho promedio del río.

\begin{tabular}{|c|c|c|c|c|c|}
\hline 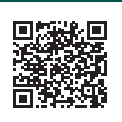 & (c) (i) \&) (2) & $\Leftrightarrow$ & 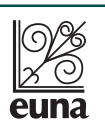 & UNA & 53 \\
\hline
\end{tabular}




\section{Revista de CIENCIAS AMBIENTALES Tropical Journal of Environmental Sciences}

Revista de Ciencias Ambientales (Trop J Environ Sci). EISSN: 2215-3896. (Enero-Junio, 2019) . Vol 53(1): 45-69. Dol: http://dx.doi.org/10.15359/rca.53-1.3 Open Access: www.revistas.una.ac.cr/ambientales EMAlL: revista.ambientales@una.ac.cr López-Mares L. M., Lozano de Poo J. M., Torre-Silva F., Rodríguez-Santiago J. y López-Fraga J. A.

Cuadro 2. Características geográficas del río Santiago por unidad de paisaje hídrico

\begin{tabular}{lccc}
\hline & $\begin{array}{c}\text { Gran } \\
\text { infraestructura }\end{array}$ & $\begin{array}{c}\text { Vialidad } \\
\text { pavimentada }\end{array}$ & Residuo \\
\hline Ubicación en el río & Aguas arriba & Aguas medias & Aguas abajo \\
Altitud (m s.n.m.) & $1935-1892$ & $1892-1852$ & $1852-1846$ \\
Ancho prom. (m) & 65 & 52.5 & 22.5 \\
Largo (km) & 3.4 & 12.8 & 1.5 \\
\hline
\end{tabular}

En el Cuadro 3 enlistamos las características generales del río Santiago. Como este muestra, aguas arriba nace el cauce de 26 afluentes con una altitud máxima aproximada de $2820 \mathrm{~m}$ s.n.m. Estos vierten sus aguas en un sistema de vasos de captación conformado por tres presas. De estos vasos, el agua es conducida hacia una potabilizadora para su posterior consumo humano.

La parte media del río tiene una extensión total de $17.7 \mathrm{~km}$, de los cuales $12.8 \mathrm{~km}$ fueron entubados y pavimentados en tres etapas: 1985, 1992 y 2016. La totalidad de esta sección del río se encuentra dentro de la mancha urbana y su cauce recorre más de 23 colonias con 84170 habitantes.

Aguas abajo, el cauce a cielo abierto se reintegra al paisaje, conduciendo parte de las aguas negras de la ZMSLP y escurrimientos pluviales. Un porcentaje de estas aguas es extraído y empleado para riego agrícola, mientras que el excedente desemboca $6 \mathrm{~km}$ después en la laguna de la Tinaja a 1827 m s.n.m. En este tramo actualmente se construye la planta tratadora El Morro, a la cual desembocarán parte de las aguas residuales de la ZMSLP para, posteriormente, ser empleadas en riego.

Cuadro 3. Características generales del río Santiago por unidad de paisaje hídrico

\begin{tabular}{|c|c|c|}
\hline Gran infraestructura & Vialidad pavimentada & Residuo \\
\hline Aguas arriba & Aguas medias & Aguas abajo \\
\hline \multicolumn{3}{|c|}{ Características generales } \\
\hline Río desemboca en vasos de captación & $\begin{array}{l}\text { El río se encuentra pavimentado y } \\
\text { soterrado }\end{array}$ & Cauce a cielo abierto \\
\hline Cauce a cielo abierto & & Características riparias degradadas \\
\hline Características riparias & $\begin{array}{l}\text { Traspatio de vivienda y comercio con } \\
\text { muros ciegos hacia el río }\end{array}$ & $\begin{array}{l}\text { Atraviesa zona rural-urbana y ali- } \\
\text { menta actividades agrícolas y gana- }\end{array}$ \\
\hline Parte de un área natural protegida & $\begin{array}{l}\text { Atraviesa la zona urbana y funge } \\
\text { como borde }\end{array}$ & deras \\
\hline \multicolumn{3}{|c|}{ Lógica } \\
\hline $\begin{array}{l}\text { "Viejo paradigma": gestión integral } \\
\text { del agua mediante grandes obras de } \\
\text { infraestructura ingenieril }\end{array}$ & $\begin{array}{l}\text { Desarrollista: transformación para } \\
\text { facilitar el crecimiento urbano y los } \\
\text { flujos vehiculares }\end{array}$ & $\begin{array}{l}\text { Residual: al dejar la mancha urbana, } \\
\text { el río conduce desechos y aguas re- } \\
\text { siduales }\end{array}$ \\
\hline
\end{tabular}

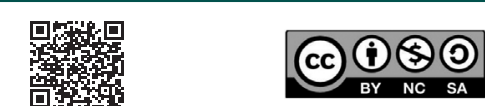

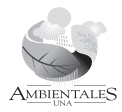




\section{Revista de

\begin{tabular}{|c|c|c|}
\hline Gran infraestructura & Vialidad pavimentada & Residuo \\
\hline Aguas arriba & Aguas medias & Aguas abajo \\
\hline \multicolumn{3}{|c|}{ Uso del espacio } \\
\hline $\begin{array}{l}\text { Almacenaje del agua, actividades } \\
\text { recreativas, deportivas y agrícolas }\end{array}$ & $\begin{array}{l}\text { Tránsito vehicular y colector pluvial } \\
\text { que capta y expulsa el agua fuera de } \\
\text { la ciudad }\end{array}$ & $\begin{array}{l}\text { Nulo uso social, cauce de aguas plu- } \\
\text { viales y residuales a cielo abierto }\end{array}$ \\
\hline \multicolumn{3}{|c|}{ Uso del agua } \\
\hline Consumo y abasto urbano & $\begin{array}{l}\text { Colector pluvial que busca acelerar } \\
\text { escurrimientos, agua como lastre, } \\
\text { promotora de riesgos }\end{array}$ & $\begin{array}{l}\text { Agrícola } \\
\text { Desechos y excedentes llegan a lagu- } \\
\text { nas de filtración, inundando comuni- } \\
\text { dades rurales }\end{array}$ \\
\hline \multicolumn{3}{|c|}{ Tipos de agua } \\
\hline Agua captada por afluentes naturales & $\begin{array}{l}\text { Agua pluvial contaminada por la } \\
\text { mixtura con aguas residuales }\end{array}$ & Agua residual \\
\hline
\end{tabular}

En resumen, el río Santiago es uno de los cauces urbanos que ha sufrido más intervenciones: aguas arriba sus escurrimientos son captados por un sistema de presas que deseca su cauce; posteriormente, bajo la lógica desarrollista, su brazo principal fue pavimentado y su última ramificación es utilizada para conducir parte de las aguas negras de la ciudad y regar campos de cultivo (ver Figura 2). El ciclo del agua (limpia y de consumo río arriba, y de desecho río abajo) es un reflejo de la estructura socioeconómica de sus colonias aledañas. Es decir, de nivel alto y medio río arriba y de nivel bajo y rural-urbano aguas abajo.

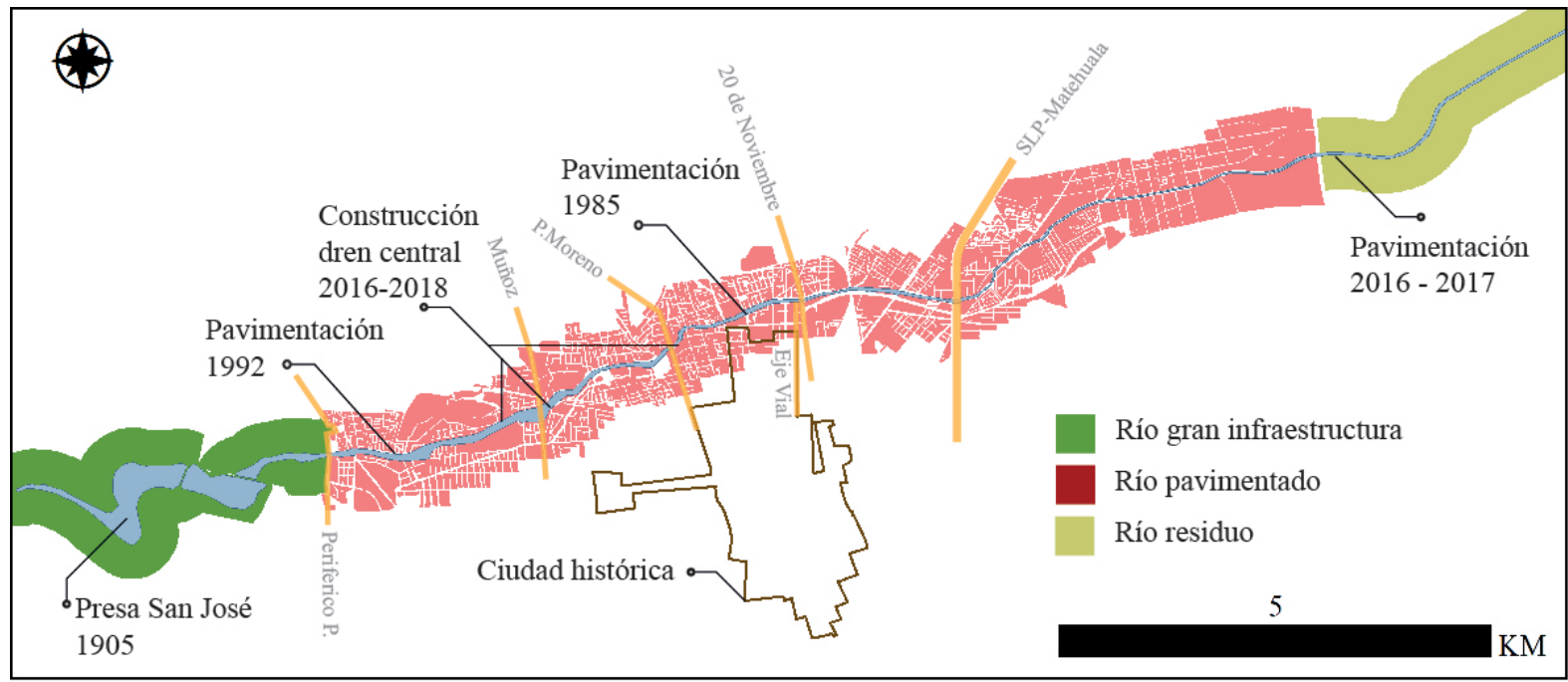

Figura 2. Unidades de paisaje hídrico del río Santiago.

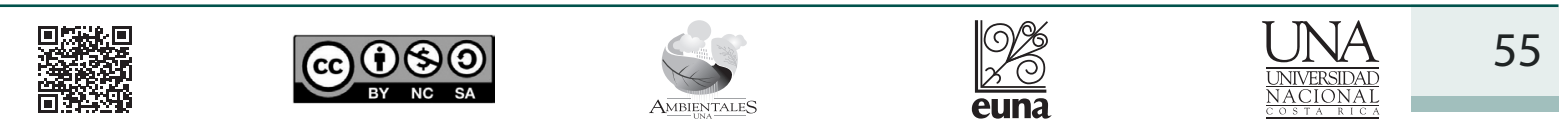




\section{Revista de CIENCIAS AMBIENTALES Tropical Journal of Environmental Sciences}

Revista de Ciencias Ambientales (Trop J Environ Sci). EISSN: 2215-3896. (Enero-Junio, 2019) . Vol 53(1): 45-69. Dol: http://dx.doi.org/10.15359/rca.53-1.3 Open Access: www.revistas.una.ac.cr/ambientales EMAlL: revista.ambientales@una.ac.cr López-Mares L. M., Lozano de Poo J. M., Torre-Silva F., Rodríguez-Santiago J. y López-Fraga J. A.

\subsection{Río Españita}

A lo largo del siglo XVIII y principios del XIX, el río Españita era considerado el cauce más importante para el abastecimiento de agua en la ciudad (Hernández-Fuentes, 2010). El significado que tenía el agua del río para sus habitantes estaba asociado directamente a los procesos y ciclos naturales. Las festividades de San Juan Bautista se realizaban en su cauce y el río representaba renovación (La Corriente, 2016). Sus aguas corrían desde el manantial de la Cañada del Lobo enclavado en la Sierra de San Miguelito, área que representa el $3.75 \%$ del total de la subcuenca San José (INEGI, 2017).

La red hídrica del río Españita se divide en dos. La primera parte está compuesta por una serie de afluentes que nacen al sur poniente de la capital y recorren diferentes colonias a manera de canal intraurbano, para luego conformar un brazo hídrico que aparentemente desembocaba en una serie de pequeños cuerpos hídricos, en lo que antes se conocía como los charcos de Santa Ana. La segunda parte, objeto de este análisis, comprende, aguas arriba, un cauce alimentado por 3 afluentes, los cuales confluyen en las inmediaciones de la presa de la Cañada del Lobo, construida en 1987. En el Cuadro 4 se muestran las características geográficas del tramo de estudio.

Cuadro 4. Características geográficas del río Españita por unidad de paisaje hídrico

\begin{tabular}{lcccc}
\hline Ubicación en el río & $\begin{array}{c}\text { Gran } \\
\text { infraestructura }\end{array}$ & $\begin{array}{c}\text { Espacio } \\
\text { social }\end{array}$ & $\begin{array}{c}\text { Vialidad } \\
\text { pavimentada }\end{array}$ & Residuo \\
\hline \multirow{2}{*}{ Altitud (msnm) } & Aguas arriba & Aguas medias & Aguas abajo \\
Ancho prom. $(\mathrm{m})$ & $1929-1893$ & \multicolumn{1}{c}{$1893-1854$} & $1854-1843$ \\
Largo $(\mathrm{km})$ & 21.5 & 2.75 & 30 \\
& 3.5 & 2.3 & 5 & 6.2 \\
\hline
\end{tabular}

Desde este punto, la parte media del río forma un solo brazo hídrico de $16.5 \mathrm{~km}$ con dirección variable. Este tramo se encuentra actualmente pavimentado; una parte alberga un parque lineal con espacios de convivencia y recreación, y otra parte es una vialidad vehicular. Finalmente, aguas abajo, el río desemboca en el Tanque Tenorio, en dónde se encuentra la planta de tratamiento de agua más grande de la ZMSLP (ver Cuadro 5).

Cuadro 5. Características del río Españita por unidad de paisaje hídrico

\begin{tabular}{|c|c|c|c|}
\hline Gran infraestructura & Espacio social & Vialidad & Residuo \\
\hline Aguas arriba & \multicolumn{2}{|c|}{ Aguas medias } & Aguas abajo \\
\hline \multicolumn{4}{|c|}{ Características generales } \\
\hline \multirow{4}{*}{$\begin{array}{l}\text { Tres afluentes del río desembocan } \\
\text { en presa Cañada del Lobo. } \\
\text { Este tramo cuenta con vestigios de } \\
\text { infraestructura del siglo XIX. }\end{array}$} & \multirow{6}{*}{$\begin{array}{l}\text { Parque lineal, con } \\
\text { actividades deportivas } \\
\text { y recreativas. } \\
\text { Lecho mayoritariamen- } \\
\text { te pavimentado. }\end{array}$} & \multirow{2}{*}{$\begin{array}{l}\text { El río se encuentra pa- } \\
\text { vimentado y soterrado }\end{array}$} & \multirow{2}{*}{$\begin{array}{l}\text { Cauce a cielo abierto } \\
\text { Características riparias degradadas. }\end{array}$} \\
\hline & & & \\
\hline & & \multirow{3}{*}{$\begin{array}{l}\text { Traspatio de vivienda } \\
\text { y comercio con muros } \\
\text { ciegos hacia el río }\end{array}$} & \multirow{4}{*}{$\begin{array}{l}\text { Atraviesa zonas agrícolas rural-ur- } \\
\text { banas y conduce aguas residuales } \\
\text { a la planta de tratamiento "Tanque } \\
\text { Tenorio". }\end{array}$} \\
\hline & & & \\
\hline \multirow{2}{*}{$\begin{array}{l}\text { Cauce a cielo abierto con caracterís- } \\
\text { ticas riparias. }\end{array}$} & & & \\
\hline & & $\begin{array}{l}\text { Atraviesa la zona urba- } \\
\text { na y funge como borde }\end{array}$ & \\
\hline
\end{tabular}

(c)

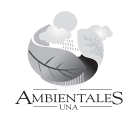




\section{Revista de

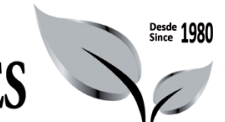 CIENCIAS AMBIENTALES Tropical Journal of Environmental Sciences}

Revista de Ciencias Ambientales (Trop J Environ Sci). EISSN: 2215-3896.

(Enero-Junio, 2019) . Vol 53(1): 45-69. D0l: http://dx.doi.org/10.15359/rca.53-1.3

Open Access: www.revistas.una.ac.cr/ambientales
EMAlL: revista.ambientales@una.ac.cr López-Mares L. M., Lozano de Poo J. M., Torre-Silva F., Rodríguez-Santiago J. y López-Fraga J. A.

\begin{tabular}{|c|c|c|c|}
\hline Gran infraestructura & Espacio social & Vialidad & Residuo \\
\hline Aguas arriba & \multicolumn{2}{|c|}{ Aguas medias } & Aguas abajo \\
\hline \multicolumn{4}{|c|}{ Lógica } \\
\hline $\begin{array}{l}\text { En el siglo XIX se conduce y canali- } \\
\text { za el agua del río } \\
\text { En el siglo XX se adopta el "viejo } \\
\text { paradigma" de gestión integral del } \\
\text { agua. }\end{array}$ & $\begin{array}{l}\text { Desarrollista: transform } \\
\text { crecimiento urbano }\end{array}$ & ación para facilitar el & $\begin{array}{l}\text { Residual: al dejar la mancha urbana, } \\
\text { el río conduce desechos y aguas } \\
\text { residuales. } \\
\text { Cíclica, el agua es tratada y reutiliza- } \\
\text { da, pero su calidad no es suficiente } \\
\text { para consumo humano. }\end{array}$ \\
\hline \multicolumn{4}{|c|}{ Uso del espacio } \\
\hline $\begin{array}{l}\text { Almacén de agua } \\
\text { Actividades recreativas, deportivas } \\
\text { y agrícolas }\end{array}$ & $\begin{array}{l}\text { Actividades recreativas } \\
\text { y deportivas } \\
\text { Punto de encuentro } \\
\text { social y borde entre } \\
\text { pandillas } \\
\text { Apropiación por jó- } \\
\text { venes }\end{array}$ & $\begin{array}{l}\text { Tránsito vehicular } \\
\text { Colector pluvial que } \\
\text { busca expulsar el agua } \\
\text { fuera de la ciudad }\end{array}$ & $\begin{array}{l}\text { Cauce de agua pluviales y residuales } \\
\text { a cielo abierto } \\
\text { Nulo uso social }\end{array}$ \\
\hline \multicolumn{4}{|c|}{ Uso del agua } \\
\hline Consumo agrícola y urbano & $\begin{array}{l}\text { El agua es un factor de } \\
\text { inundaciones } \\
\text { No se le da un uso, por } \\
\text { expulsión de la ciudad } 1\end{array}$ & $\begin{array}{l}\text { iesgo: contaminación e } \\
\text { el contrario, se busca la } \\
\text { o más rápido posible. }\end{array}$ & Uso agrícola \\
\hline \multicolumn{4}{|c|}{ Tipos de agua } \\
\hline $\begin{array}{l}\text { Agua captada por afluentes natu- } \\
\text { rales }\end{array}$ & Agua pluvial contamin & & $\begin{array}{l}\text { Agua residual. } \\
\text { Agua tratada. }\end{array}$ \\
\hline
\end{tabular}

El parque lineal alberga actividades deportivas y recreativas y espacios públicos en constante uso que promueven la cohesión y convivencia social, y permiten la apropiación y cambio de significado del río a través de su utilización cotidiana. Sin embargo, estos espacios también son de pugna entre pandillas de colonias aledañas. Aguas abajo, como se mencionó anteriormente, el río, ya como canal a cielo abierto, transporta agua pluvial contaminada y aguas negras hacia la planta de tratamiento (Ver Figura 3). El paisaje en este tramo da cuenta del impacto que ha tenido el crecimiento urbano a través del intercambio de áreas de uso de suelo agrícola por áreas urbanizables de alto riesgo para sus habitantes. 

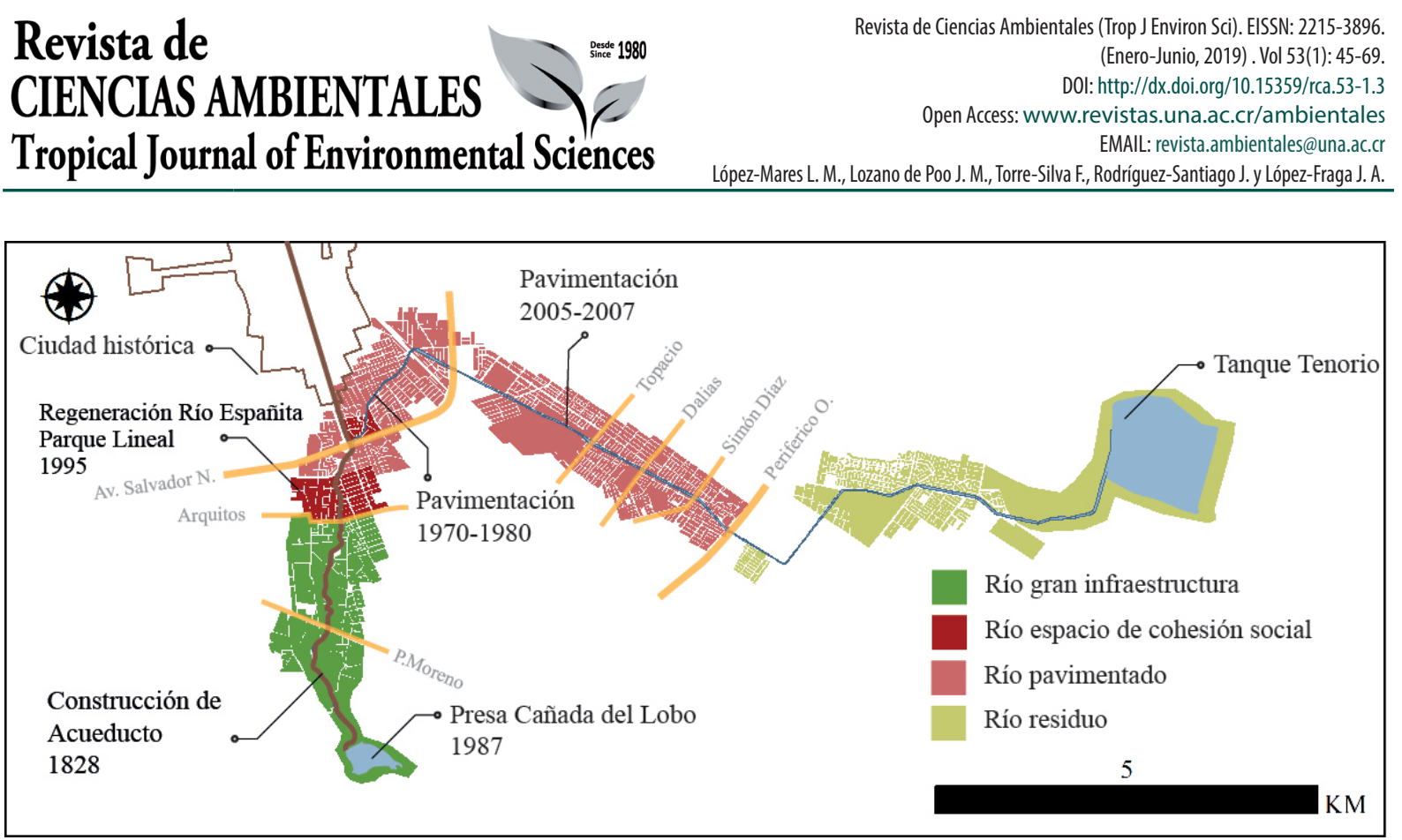

Figura 3. Unidades de paisaje hídrico del río Españita.

Si comparamos el río Españita con el río Santiago, podemos ver la repetición de patrones y de unidades de paisaje hídrico, que si bien difieren en escala, las transformaciones operan desde lógicas muy similares. Aguas arriba, el paisaje moderno con grandes infraestructuras convive con intervenciones de menor escala, pero que igualmente buscaron gestionar el recurso desde el siglo XIX. En su parte media, con una lógica desarrollista, el cauce fue urbanizado; $5 \mathrm{~km}$ fueron convertidos en vialidad para el flujo de vehículos motorizados y $2.3 \mathrm{~km}$ en parque lineal. En consecuencia, los usos del espacio son radicalmente distintos. El tramo vial del río se caracteriza por su transformación en un no lugar (Augé, 1996), es decir, en un espacio de circulación, de distribución y comunicación motorizado, que impide la integración de peatones y ciclistas. Estos espacios son manifestaciones de la relación que los individuos mantienen con el lugar que habitan, y dan cuenta de la pérdida del vínculo social entre las personas y el espacio público constitutivo de las ciudades (Augé, 1996; Jacobs, 1967).

\subsection{Río Paisanos}

El río Paisanos corre casi paralelo al Santiago, $4.2 \mathrm{~km}$ al norte. A diferencia de los ríos anteriores, ninguno de sus tramos ha sido pavimentado, por lo que conserva flora y fauna riparia a lo largo de todo su cauce. Sin embargo, tanto los ríos que lo alimentan como su cauce han sufrido alteraciones derivadas de la actividad agrícola y del crecimiento urbano.

La cuenca del este río se divide en tres: río arriba, al este, el cauce es alimentado por 5 afluentes tributarios, cuya altitud y extensión máxima es de 2478 m s.n.m. y 38 km respectivamente, y confluyen en la intersección del río con la carretera Zacatecas. En este tramo el río recorre

\begin{tabular}{|c|c|c|}
\hline 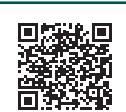 & (c) (i) (5) (2) & 58 \\
\hline
\end{tabular}




\section{Revista de CIENCIAS AMBIENTALES Tropical Journal of Environmental Sciences}

Revista de Ciencias Ambientales (Trop J Environ Sci). EISSN: 2215-3896.

(Enero-Junio, 2019) . Vol 53(1): 45-69.

Dol: http://dx.doi.org/10.15359/rca.53-1.3

Open Access: www.revistas.una.ac.cr/ambientales

EMAlL: revista.ambientales@una.ac.cr

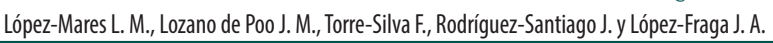

campos agrícolas, por lo que alimenta canales de riego. Además, recibe un canal que desvía el agua del río las Vírgenes, que antes desembocaba en el río Santiago, hacia el río Paisanos, esto con el fin de desahogarlo. A partir de ahí, el río Paisanos forma un solo brazo hídrico y sigue su curso hacia el nororiente hasta girar hacia el norte. Este giro fue hecho a finales del siglo XIX para permitir la construcción de la vía férrea San Luis-Laredo. Este tramo desemboca en pequeñas lagunas de inundación cerca del relleno sanitario de Milpillas y es el tramo intraurbano en el que se concentra este análisis. Finalmente, el río Paisanos reaparece a unos kilómetros de las lagunas de inundación, recorriendo 15 kilómetros aproximadamente de campos de cultivo y áreas silvestres para desembocar en las lagunas del Palmarito, Arenas y Cerro Prieto, a una altitud de $1824 \mathrm{~m}$ s.n.m. en donde también desemboca el río Santiago.

La parte intermedia del río, objeto de este estudio, tiene una longitud de $8.72 \mathrm{~km}$. Su cauce recorre 14 colonias con una población total de 34140 personas. Algunas de estas colonias presentan características rural-urbanas. A saber, sus habitantes realizan actividades agrícolas y ganaderas por la presión urbana. Otras colonias, netamente urbanas, tienen en común una alta densidad de población y nivel socio-económico bajo. Los Cuadros 6 y 7 muestran las características principales de este río.

Cuadro 6. Características geográficas del río Paisanos por unidad de paisaje hídrico

\begin{tabular}{lccc}
\hline & Residuo-uso rural & Residuo-traspatio & Residuo-fachada fluvial \\
\hline Ubicación en el río & Aguas arriba & Aguas medias & Aguas abajo \\
Altitud (m s.n.m.) & $1935-1892$ & $1892-1852$ & $1852-1846$ \\
Ancho prom. (m) & 65 & 52.5 & 22.5 \\
Largo (km) & 3.4 & 12.8 & 1.5 \\
\hline
\end{tabular}

Cuadro 7. Características generales del río Paisanos por unidad de paisaje hídrico

\begin{tabular}{|c|c|c|}
\hline Residuo- uso rural & Residuo-traspatio & Residuo-fachada fluvial \\
\hline Aguas arriba & Aguas medias & Aguas abajo \\
\hline \multicolumn{3}{|c|}{ Características generales } \\
\hline $\begin{array}{l}\text { Cauce natural degradado, contamina- } \\
\text { do por actividades ganaderas }\end{array}$ & \multicolumn{2}{|c|}{ Cauce natural degradado, contaminado por actividades urbanas } \\
\hline $\begin{array}{l}\text { Abundante flora riparia } \\
\text { Rodeado predominantemente por un }\end{array}$ & \multicolumn{2}{|c|}{$\begin{array}{c}\text { Rodeado de urbanización fragmentada; conjuntos de vivienda social, colonias de } \\
\text { vivienda progresiva, lotes baldíos y parches rural-urbanos }\end{array}$} \\
\hline $\begin{array}{l}\text { entorno rural y actividades agrícolas } \\
\text { En algunos segmentos es un borde en- } \\
\text { tre actividad comercial, industrial, bo- } \\
\text { degas y vivienda progresiva }\end{array}$ & $\begin{array}{l}\text { Las construcciones aledañas al río le } \\
\text { dan la espalda mediante cercas y mu- } \\
\text { ros ciegos }\end{array}$ & $\begin{array}{l}\text { El entorno construido y el río se encuen- } \\
\text { tran articulados por medio de áreas de } \\
\text { equipamiento público abiertas y cerra- } \\
\text { das }\end{array}$ \\
\hline
\end{tabular}

\begin{tabular}{|c|c|c|}
\hline 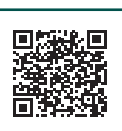 & (c) (1) ()(2) (2) & 59 \\
\hline
\end{tabular}




\section{Revista de
CIENCIAS AMBIENTALES Tropical Journal of Environmental Sciences}

Revista de Ciencias Ambientales (Trop J Environ Sci). EISSN: 2215-3896. (Enero-Junio, 2019) . Vol 53(1): 45-69. Dol: http://dx.doi.org/10.15359/rca.53-1.3 Open Access: www.revistas.una.ac.cr/ambientales EMAlL: revista.ambientales@una.ac.cr López-Mares L. M., Lozano de Poo J. M., Torre-Silva F., Rodríguez-Santiago J. y López-Fraga J. A.

\begin{tabular}{ccc}
\hline Residuo- uso rural & Residuo-traspatio & Residuo-fachada fluvial \\
\hline Aguas arriba & Aguas medias & Aguas abajo \\
\hline Lógica \\
\hline \multicolumn{2}{c}{ Residual: el río como repositorio de desechos (basura y desagües) } \\
\hline & Uso del espacio \\
\hline
\end{tabular}

Río como no lugar o espacio carente de actividad social.

El borde y lecho del río son usados como relleno sanitario

Solo en ciertas épocas, el río es usado para llevar a cabo actividades recreativas

Lugar de tránsito para cruzar de un lado a otro

Frente a la unidad deportiva, el río fue

Espacio de reunión de delincuentes, personas borrachas y parejas. utilizado como lugar para correr y hacer ejercicio.

\section{Uso del agua}

El agua que corre por el río es intermitente y se contamina a su paso por las actividades agrícolas, ganaderas y urbanas aledañas.

Parte de esta agua, sin embargo, se filtra de manera natural al manto poco profundo del cual algunas familias vecinas extraen agua mediante pozos.

Tipos de agua

Agua de afluentes naturales, contaminada a su paso por aguas residuales, desechos orgánicos e inorgánicos vertidos en el río.

Cabe mencionar que además de encontrarse enclavado en una periferia empobrecida, el río Paisanos es también el más alejado del centro histórico de San Luis Potosí, por lo que el crecimiento urbano alcanzó y rebasó sus bordes hasta hace algunas décadas. Además de las transformaciones antes mencionadas, los intereses económicos en el sitio han sido pocos, de ahí que el río se encuentre en un mayor estado natural y que no registre obras planificadas. A diferencia de los otros ríos, ni la lógica moderna ni la lógica desarrollista se han impuesto sobre el río Paisanos. Sin embargo, como los otros dos, este río es el traspatio de su contexto inmediato. Desde la lógica residual, encontramos a lo largo de todo su cauce basura en sus bordes y lecho, así como la percepción social generalizada del río como un no lugar, inseguro e intransitable.

Por lo tanto, para entender al río Paisanos, segmentamos su cauce en unidades de paisaje que lejos de ser homogéneas, reflejan la forma en cómo este se relaciona con su contexto. Los bordes del río Paisanos (densos en vegetación) han sido límites que separan grandes contrastes. Río arriba predomina la actividad agrícola, mientras que, río abajo, sirve para estructurar parches de crecimiento urbano fragmentados e inconexos. En ellos encontramos lotes baldíos, vivienda social, progresiva y rural; así como industria y actividades agrícolas que se relacionan de dos formas principales al río: 1) dándole la espalda mediante muros ciegos construidos al borde de su lecho y 2) articulándose a él mediante áreas de equipamiento y fachadas fluviales (ver la Figura 4).

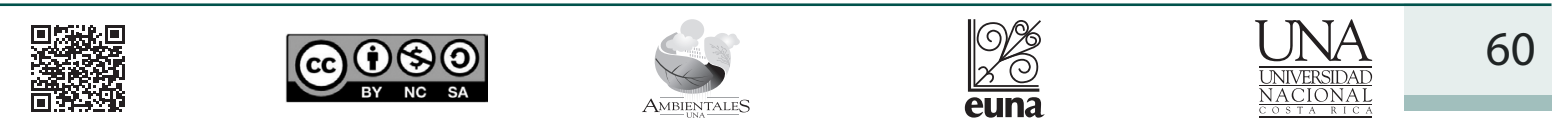




\section{Revista de CIENCIAS AMBIENTALES Tropical Journal of Environmental Sciences}

Revista de Ciencias Ambientales (Trop J Environ Sci). EISSN: 2215-3896.

(Enero-Junio, 2019) . Vol 53(1): 45-69.

Dol: http://dx.doi.org/10.15359/rca.53-1.3

Open Access: www.revistas.una.ac.cr/ambientales EMAIL: revista.ambientales@una.ac.c López-Mares L. M., Lozano de Poo J. M., Torre-Silva F., Rodríguez-Santiago J. y López-Fraga J. A.

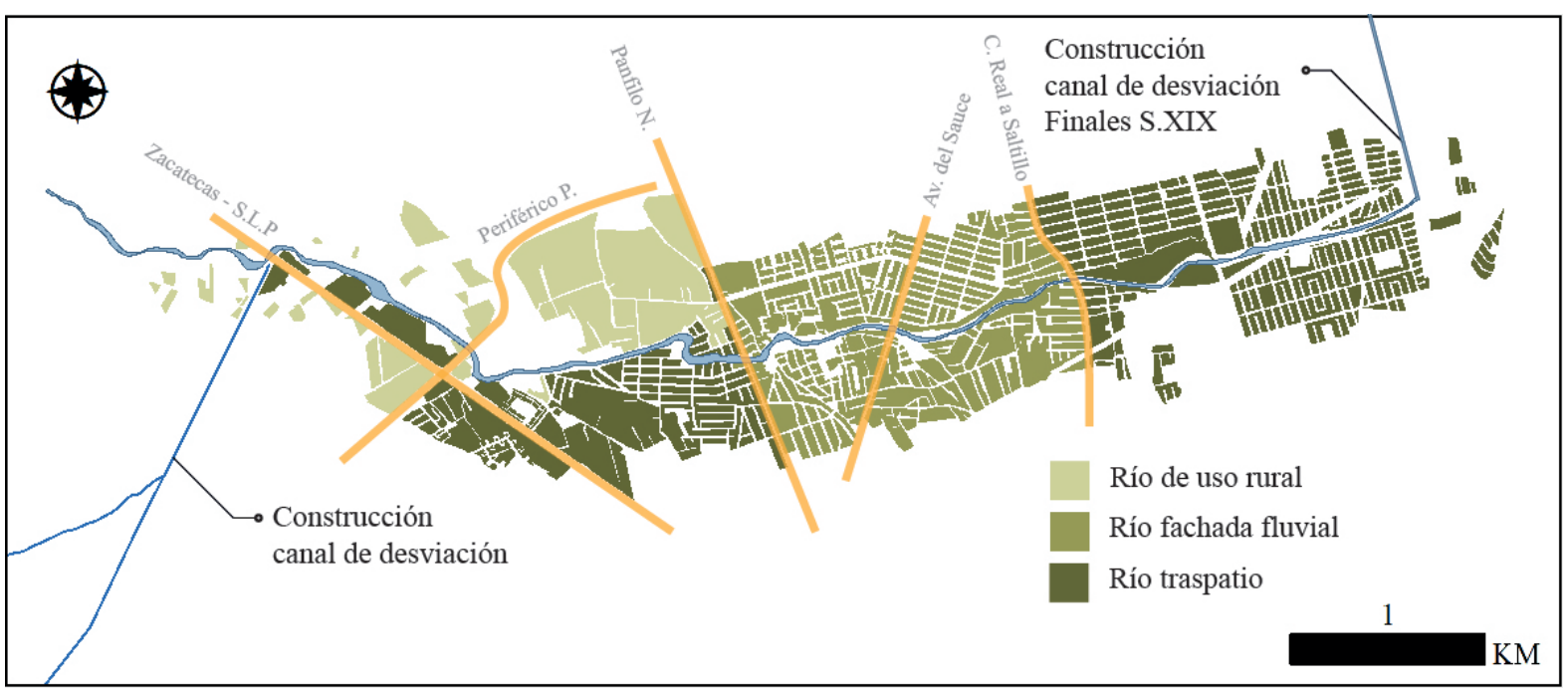

Figura 4. Unidades de paisaje hídrico del río Paisanos.

En resumen, los tres ríos estudiados presentan características muy distintas. Dentro de la ZMSLP, el río Santiago se encuentra pavimentado en su totalidad, impidiendo su uso social; el río Españita se está parcialmente pavimentado como vialidad y otra como espacio social de convivencia; y el río Paisanos es el único cuyo cauce no ha sido urbanizado hasta el momento.

\section{Paisajes hidro-sociales en la ZMSLP}

Con base en las unidades de paisaje identificadas en cada río, a continuación analizamos los híbridos resultantes de la compleja y dialéctica relación naturaleza-sociedad y su materialización en el espacio urbano.

\subsection{Los ríos como infraestructura hídrica}

A lo largo de la historia, el control sobre la gestión del agua ha sido esencial para la supervivencia de las ciudades. Sin embargo, las infraestructuras para su aprovechamiento han cambiado de obras a pequeña escala que captaban y conducían el recurso a grandes obras de almacenamiento, expulsión y desvío para facilitar el crecimiento urbano.

Las grandes infraestructuras hidráulicas en la ZMSLP fueron construidas entre 1905 y 1988. En el cauce del río Santiago se creó un sistema de tres presas: San José (1828 y 1905), Peaje (1949-1950) y Potosino (1985-1988) y en el río Españita se construyó la presa de la Cañada del Lobo sobre el antiguo manantial (Padrón-Moncada, 2014) (Figura 5). Estas obras redujeron los escurrimientos de los ríos y los convirtieron en cauces secos y repositorios de desechos urbanos. Sin embargo, se reconoce que este tipo de obras se han integrado al paisaje de formas

\begin{tabular}{|c|c|c|}
\hline 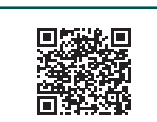 & (c) (1) @) (2) & 61 \\
\hline
\end{tabular}




\section{Revista de CIENCIAS AMBIENTALES Tropical Journal of Environmental Sciences}

Revista de Ciencias Ambientales (Trop J Environ Sci). EISSN: 2215-3896. (Enero-Junio, 2019) . Vol 53(1): 45-69. D0l: http://dx.doi.org/10.15359/rca.53-1.3 Open Access: www.revistas.una.ac.cr/ambientales EMAlL: revista.ambientales@una.ac.cr López-Mares L. M., Lozano de Poo J. M., Torre-Silva F., Rodríguez-Santiago J. y López-Fraga J. A.

insospechadas. Sus cortinas de piedra han fomentado usos recreativos y deportivos relacionados con el agua.
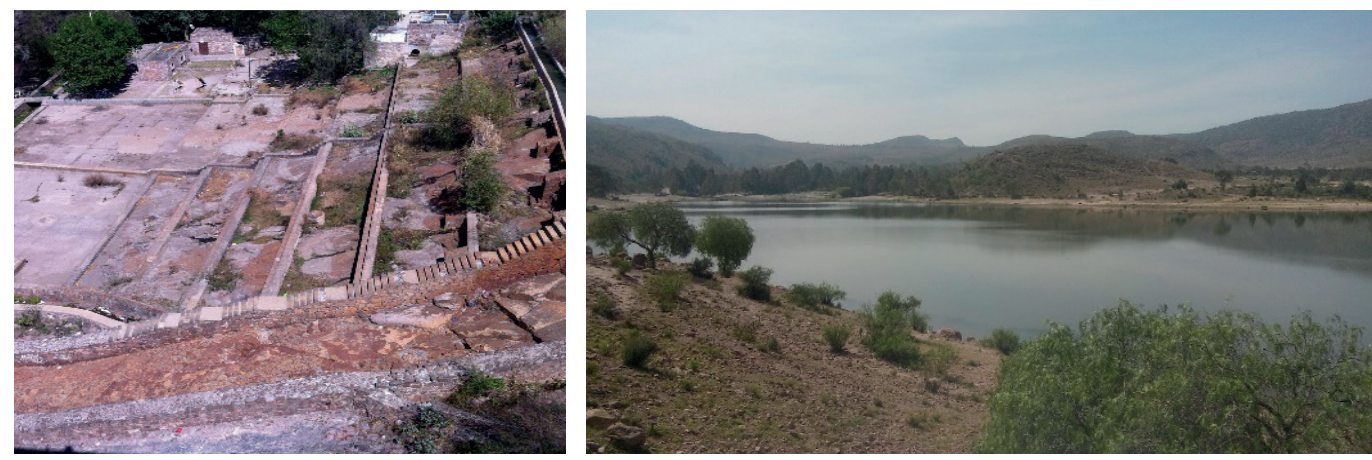

Figuras 5. Presas San José y Cañada del Lobo. Fuente: Kristoffer Toerstady, en "A Motorway Called Río".

\subsubsection{Los ríos como vialidades: El caso del río Santiago}

Ya desde la década de 1950, se contemplaba la construcción de un boulevard en el cauce del río Santiago. Según una nota periodística de 1954:

La Secretaría de Comunicaciones y Obras Públicas se propone aprovechar el cauce del río de Santiago construyendo en él un boulevard que dará fácil acceso a la Carretera Central... $\mathrm{Al}$ aprovecharse el cauce del río mencionado, la ciudad se evita un basurero más, en tanto que Municipio se ahorra varias decenas de miles de pesos... (Sol de San Luis, 1954)

De esta manera, tres décadas antes de que se ejecutara la obra, el discurso público ya identificaba al río como una fuente de contaminación, cuyo potencial como elemento urbano beneficiaría más a la población como vialidad que como elemento natural.

Este discurso, reproducido no solamente en la ZMSLP, sino en múltiples ciudades dentro y fuera de México, fomentó la canalización y pavimentación de muchos cauces urbanos, ignorando las funciones medioambientales de los sistemas riparios en entornos urbanos. Actualmente, por el boulevard río Santiago circulan diariamente cerca de 45000 vehículos (Figura 6). Sin embargo, por él no transita el transporte público, ni es accesible a medios no motorizados de transporte, por lo que ofrece sus servicios exclusivamente al $30 \%$ de la población, la cual posee vehículos privados, excluyendo al $70 \%$ restante de habitantes (ITDP, 2017).

Las condiciones actuales de los ríos en la ZMSLP reflejan, de manera clara, la tensión existente entre el crecimiento urbano y el entorno natural (Figura 6). De los tres ríos, el que mejor ilustra este fenómeno es el río Santiago, cuya extensión dentro de la mancha urbana se encuentra totalmente pavimentada.

\begin{tabular}{|c|c|c|}
\hline 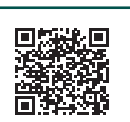 & (c) (1) @) (2) & 62 \\
\hline
\end{tabular}




\section{Revista de CIENCIAS AMBIENTALES Tropical Journal of Environmental Sciences}
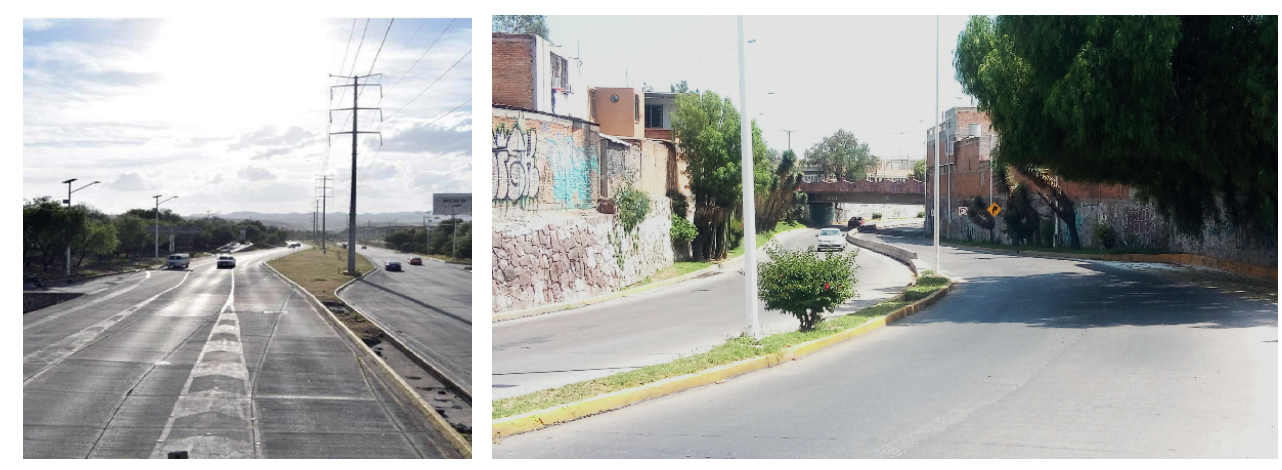

Figura 6. Fotografías de áreas pavimentados del río Santiago (izquierda) y río Españita (derecha). Fuente: Bérénice Rigal en "A Motorway Called Río".

\subsubsection{Los ríos como espacios de cohesión social: El caso del río Españita}

Pocos son los ejemplos de transformaciones del paisaje hídrico de la ZMSLP en favor de la interacción de sus habitantes en espacios públicos diseñados específicamente para el esparcimiento, la convivencia y la cohesión social. Los parques lineales del río Españita son un ejemplo claro de este tipo de intervenciones. Estas fueron realizadas en 1995, debido a la situación de abandono en la que se encontraba el río. Las viviendas construidas a lo largo de los bordes del cauce le daban la espalda y en él se concentraban basura y desechos. La imagen del río cambió a partir de su transformación en parque lineal ( $5 \mathrm{~km}$ en dos secciones), el cual alberga áreas de convivencia, culturales y deportivas, que favorecen a más de 15 mil personas (Figura 7).

Si bien actualmente este parque lineal es un borde defendido por las diferentes bandas rivales de un lado y otro de su rivera, existen actores locales que alientan su cuidado y limpieza, promoviendo eventos deportivos dirigidos a jóvenes de la zona. Estas actividades incentivan la apropiación del espacio e integran a las poblaciones de ambos lados del río; con ello ha cambiado su significado de bordo a enlace y punto de encuentro (Lynch, 1960).

Cabe destacar que aún y cuando el uso es distinto al de los tramos pavimentados como vialidad vehicular, la lógica detrás de la transformación del río en parque es similar. A saber, es una intervención modernizadora del espacio mediante pavimento, con elementos que se sobreponen en el lecho del río y bloquean su permeabilidad, aceleran escurrimientos y reducen la flora y fauna riparias; por lo tanto, disminuyen considerablemente los beneficios ecosistémicos que debiera aportar a su entorno.

\begin{tabular}{|c|c|c|}
\hline 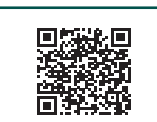 & (c) (1) @) (2) & 63 \\
\hline
\end{tabular}




\section{Revista de CIENCIAS AMBIENTALES Tropical Journal of Environmental Sciences}
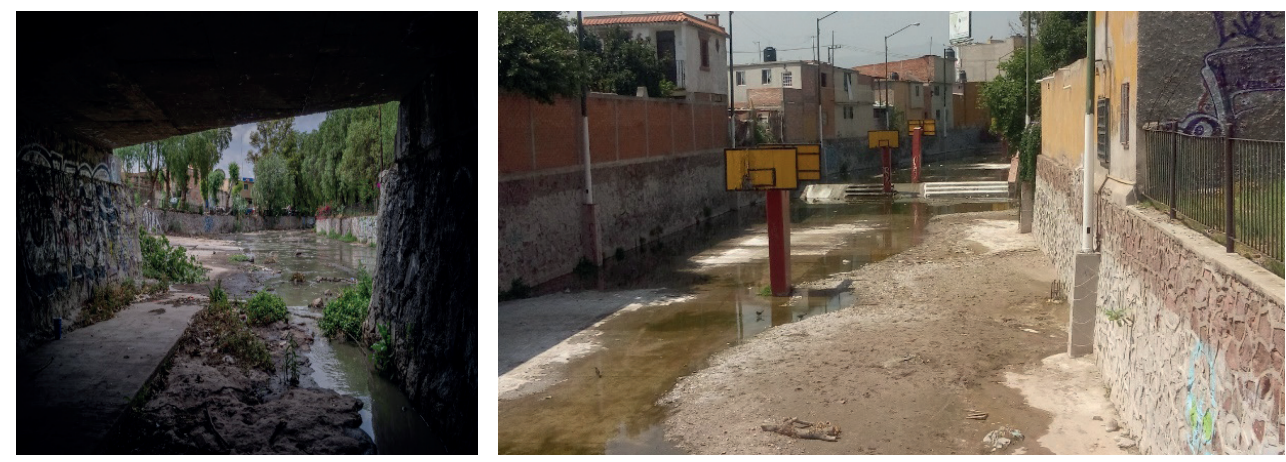

Figura 7. Segmentos de uso social del río Españita

\subsection{Los ríos como espacios residuales}

Esta unidad de paisaje se refiere a segmentos de los ríos que no han estado sujetos ni a la lógica modernizadora ni a la lógica desarrollista, sino que conservan su lecho natural. Aunque esta condición pudiera parecer positiva, estos segmentos son también repositorios de basura que conducen las aguas de desecho junto con las escorrentías pluviales contaminadas tanto de las secciones pavimentadas como de las actividades urbanas y agropecuarias aledañas (Figura 8). Por esta razón, se encuentran en estado de degradación, con diferentes problemas asociados como contaminación, erosión y baja calidad de agua (Figura 8). Además de estos problemas ecológicos, la percepción social del río como residuo es negativa. Según entrevistas con vecinos y vecinas del río Paisanos, y en línea con Perló y Zamora (2017), encontramos que perciben el río como foco de contaminación e inseguridad que promueve actividades delictivas en espacios públicos.

En la ZMSLP, el río como espacio residual incluye los tramos aguas abajo de los ríos Santiago y Españita, los cuales conducen las escorrentías de los drenes pluviales construidos debajo de sus tramos pavimentados y el drenaje de zonas aledañas. El río Paisanos es el único cauce urbano no pavimentado, es decir, de principio a fin dentro de la mancha urbana, es repositorio de drenajes y basura. Las escorrentías de este río, a diferencia de los otros dos, no han sido captadas mediante presas para fines urbanos, sino que han sido redistribuidas en el territorio por medio de una red de canales de uso agrícola. Es así como este río carece del espacio social que la presa San José y la Cañada del Lobo han generado; en contraste, su cauce no ha sido desecado, conserva una densa vegetación en sus bordes y su lecho pedregoso permite aún la infiltración de agua al subsuelo.

El carácter rural que tenía el río hasta antes de que el crecimiento urbano alcanzara y rebasara sus bordes, aún está presente en el sector poniente del río, en donde campos de cultivo y uso ganadero con vivienda rural predominan sobre un paisaje de crecimiento fragmentado. Este paisaje caracteriza al resto de los sectores, en los cuales usos habitacionales, comerciales y de

\begin{tabular}{|c|c|c|}
\hline 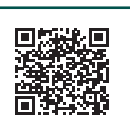 & (c) (1) (s) (2) & 64 \\
\hline
\end{tabular}




\section{Revista de CIENCIAS AMBIENTALES Tropical Journal of Environmental Sciences}

Revista de Ciencias Ambientales (Trop J Environ Sci). EISSN: 2215-3896. (Enero-Junio, 2019) . Vol 53(1): 45-69. D0l: http://dx.doi.org/10.15359/rca.53-1.3 Open Access: www.revistas.una.ac.cr/ambientales EMAlL: revista.ambientales@una.ac.cr López-Mares L. M., Lozano de Poo J. M., Torre-Silva F., Rodríguez-Santiago J. y López-Fraga J. A.

industria ligera se insertan como parches en tierras agrícolas y silvestres. De estos usos, algunos fragmentos de vivienda social se han articulado al río por medio de equipamiento, pero el resto da la espalda al río y vierte en él sus aguas residuales.

En resumen, el río como espacio residual conserva sus características naturales; sin embargo, estas se han transformado gradualmente a diferentes grados en el contexto urbano, situación que desequilibra el sistema hídrico de la región, además de exponer a sus habitantes a situaciones de alto riesgo por inundaciones y contaminación.
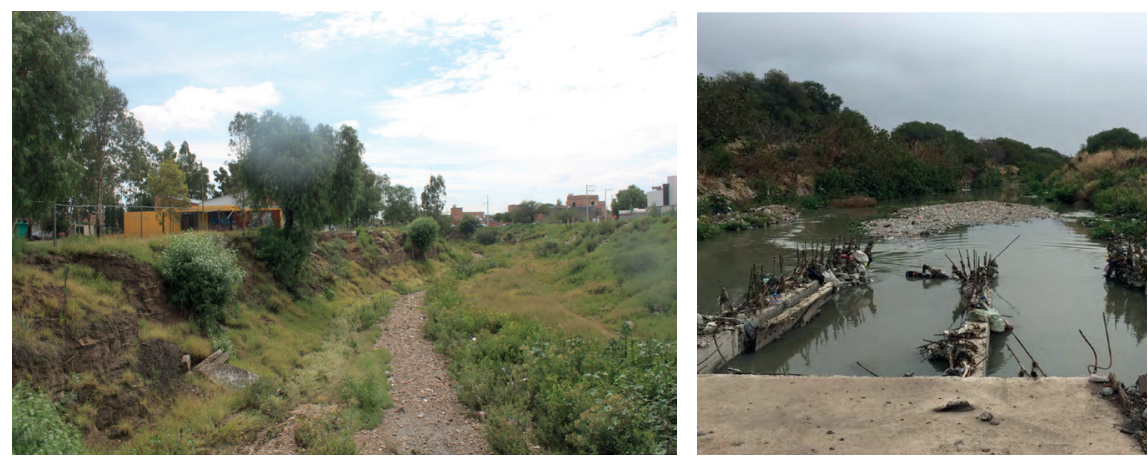

Figura 8. Evidencia de espacios residuales del río Paisanos y del río Santiago. Fuente: Kong Chin Wau en “ $A M o$ torway Called Río".

\section{Discusión de los casos}

En este trabajo analizamos los tres cauces más importantes de la ZMSLP como elementos de un sistema complejo dentro de la producción espacial. El río Paisanos es el único que conserva su flora riparia, pero se encuentra en estado de abandono y degradación. El manejo del agua en este cauce responde al uso agrícola y se gestiona de manera local, mientras que en los otros dos ríos, las grandes obras de infraestructura transformaron profundamente sus cauces, usos y significado. Sin embargo, en todos los casos se encontraron transformaciones en la estructura natural del río y sus escurrimientos. Por otro lado, el uso social de los ríos es muy distinto. En el río Españita, este uso se encuentra en el cauce; en el río Paisanos estos espacios se localizan en sus bordes, articulando las viviendas con el río; y en el caso del río Santiago el uso social se presenta fuera del cauce en colonias aledañas.

En los tres casos, los ríos han sido primero límites de crecimiento y expansión urbana, para después de haber sido rebasados sus límites, convertirse en bordes cuyo contexto social les da la espalda. Más allá, dos de los tres cauces estudiados han sido pavimentados con una lógica desarrollista, generadora de externalidades e ignorante de su potencial como equipamientos y espacios naturales para la ciudad. Solo en el caso del río Españita, una parte de las obras de pavimentación buscó beneficio social, el resto privilegió el uso y dominio vehicular. Cabe destacar que las transformaciones de los ríos se han acompañado de una expansión urbana desmedida y

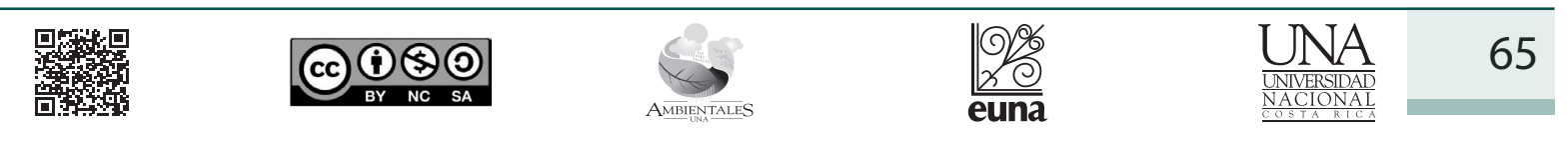


un crecimiento demográfico exponencial, la deforestación y erosión de suelos, la impermeabilización de áreas de recarga y la sobreexplotación del acuífero profundo.

Este análisis permite entender cómo el vínculo social con los elementos naturales, como fuentes de vida, se ha roto. Actualmente los cauces son percibidos como fuente de contaminación e inseguridad, y más útiles como elementos urbanos que naturales. Este cambio de percepción explica por qué los cauces se encuentran fragmentados de forma física y simbólica. Tres de los factores determinantes de esta ruptura son: en primer lugar, la degradación de los ríos, convertidos en traspatios y desagües, receptores del desecho urbano (ríos como espacios residuales); en segundo lugar, la edificación de presas y obras hídricas para el desvío y canalización de sus aguas (ríos como infraestructura hídrica), como estrategia para facilitar el crecimiento urbano y complementar su abastecimiento; por último, la decisión de pavimentar los ríos para convertirlos en parques lineales y vialidades de flujo vehicular (ríos pavimentados como vialidades y espacios de cohesión social).

Las propuestas actuales para intervenir los ríos en la ciudad, por parte del sector público, apuntan a la lógica dominante de los viejos paradigmas. Tres proyectos hídricos y urbanos de gran envergadura han sido anunciados por el Gobierno del Estado: la construcción de un segundo piso vial sobre el río Santiago, la extensión de la huella hídrica de la ciudad mediante la canalización de las aguas del río Pánuco, ubicado a $300 \mathrm{~km}$ de la ZMSLP, y la construcción de una presa llamada las Escobas, en la cuenca del río Santiago. Mientras que los dos primeros fueron anunciados como proyectos a largo plazo, el tercero ya se encuentra en proceso de construcción.

\section{Conclusiones}

Este trabajo tuvo por objetivo entender los objetos híbridos resultantes de la compleja relación naturaleza-sociedad. Estos híbridos, caracterizados como unidades de paisaje hidro-social, nos permitieron entender las lógicas, usos del espacio y del agua, así como los tipos de agua producidos por esta relación. Los hallazgos nos dan pistas para proponer alternativas que regeneren el vínculo entre las personas, el espacio urbano y el paisaje hídrico. El trabajo buscó también resaltar los beneficios a mediano y largo plazo de la revalorización de los cauces intraurbanos en relación con el bienestar y seguridad de sus habitantes. En esta línea, se hace un llamado hacia la recuperación de los ríos urbanos como ejes de equipamiento y recreación, que restablezcan el vínculo sociedad-recurso natural; generen paisajes hídricos humanos y reduzcan riesgos por inundación.

Los tres ríos de la ZMSLP cuentan con espacios potenciales para restablecer este vínculo. Intervenciones a gran escala para rehabilitar los ríos Santiago y Españita o convertir el Paisanos en un eje verde de equipamiento parecen inviables, no solo por su alto costo, sino también porque, desde el sector público, los paradigmas desarrollistas parecerían inmutables. Sin embargo, intervenciones comunitarias a pequeña escala como las impulsadas actualmente en el río Paisanos por un colectivo ciudadano podrían ser llevadas a cabo en los tres ríos. Sin importar la escala, estas intervenciones deberían pugnar por la integración digna del paisaje natural al crecimiento

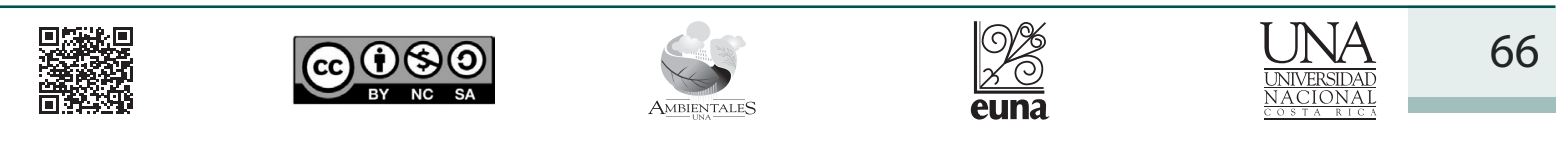




\section{Revista de CIENCIAS AMBIENTALES Tropical Journal of Environmental Sciences}

Revista de Ciencias Ambientales (Trop J Environ Sci). EISSN: 2215-3896. (Enero-Junio, 2019) . Vol 53(1): 45-69. DOl: http://dx.doi.org/10.15359/rca.53-1.3 Open Access: www.revistas.una.ac.cr/ambientales EMAIL: revista.ambientales@una.ac.cr López-Mares L. M., Lozano de Poo J. M., Torre-Silva F., Rodríguez-Santiago J. y López-Fraga J. A.

urbano (y viceversa), apelando a transformar la percepción actual y uso que se les da a los ríos. Así mismo, la gestión del agua superficial debe incluir acciones a escala micro y macro, con el fin de aprovechar los escurrimientos de manera local mediante infraestructura verde (recolección de agua pluvial a nivel doméstico y pozos de absorción que infiltren el agua de forma local). Es importante resaltar la relevancia del río Paisanos como cauce que aún no ha sido urbanizado y que, por lo tanto, cuenta con un gran potencial como elemento verde dentro de la ciudad.

De este trabajo derivan múltiples líneas de investigación futuras, tales como un análisis de la percepción ciudadana de los ríos, con el fin de entender el constructo social que ha cimentado las transformaciones de los cauces. Otra veta de investigación es la transformación a través del tiempo del uso de suelo en torno a los ríos, con el objetivo de evaluar la pérdida de área agrícola en favor de la urbanización y autonomía alimentaria en zonas semirrurales al borde de los ríos, así como los patrones de desarrollo detonados por estos ejes verdes.

\section{Agradecimientos}

Damos las gracias al Colectivo Pies sobre la Tierra, a la Universidad de Oslo y al Ingeniero Ezequiel Durán de INTERAPAS, San Luis Potosí por su apoyo en la recolección de datos de esta investigación. Agradecemos también el apoyo de la Universidad Autónoma de San Luis Potosí en la realización de este estudio. Finalmente, agradecemos los valiosos aportes de nuestras personas revisoras anónimas en la mejora de este artículo.

\section{Referencias}

Augé, M. (1996). Los no lugares, espacios del anonimato. Antropología sobre modernidad. Barcelona: Gedisa.

CONAGUA. (2009). Estudio del manejo de las aguas pluviales en la zona metropolitana de la ciudad de San Luis Potosí. Informe Ejecutivo. Estado de San Luis Potosí.

Contreras, C., \& Galindo, M. G. (2008). Abasto futuro de agua potable, análisis espacial y vulnerabilidad de la ciudad de San Luis Potosí, México. Cuadernos de Geografía, 17, 127. https:// doi.org/10.15446/rcdg.n17.10923

Dallman, S., Piechota, T. C., \& Green, D. (1999) Storm water: asset not liability Los Angeles, California: The Los Angeles \& San Gabriel Rivers Watershed Council.

Damonte, G. H. (2015). Redefiniendo territorios hidrosociales: Control hídrico en el valle de Ica, Perú (1993-2013). Cuadernos de Desarrollo Rural, 12(76), 109-133. https://doi.org/10.11144/ Javeriana.cdr12-76.rthc

El Informador. (2010, diciembre 20). Entubados, $88 \%$ de ríos y arroyos en la ciudad. El Informador.mx. Recuperado de http://www.informador.com.mx/jalisco/2010/257928/6/entubados88-de-rios-y-arroyos-en-la-ciudad.htm

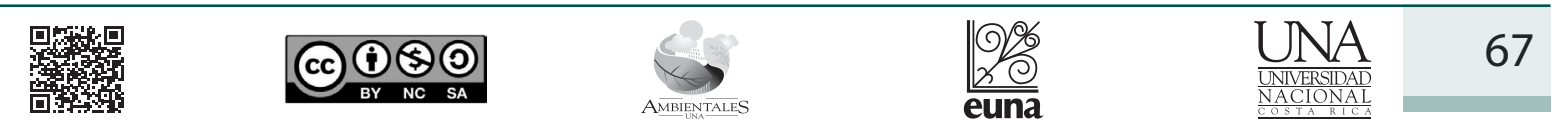




\section{Revista de CIENCIAS AMBIENTALES Tropical Journal of Environmental Sciences}

Revista de Ciencias Ambientales (Trop J Environ Sci). EISSN: 2215-3896. (Enero-Junio, 2019) . Vol 53(1): 45-69. D0l: http://dx.doi.org/10.15359/rca.53-1.3 Open Access: www.revistas.una.ac.cr/ambientales EMAIL: revista.ambientales@una.ac.cr López-Mares L. M., Lozano de Poo J. M., Torre-Silva F., Rodríguez-Santiago J. y López-Fraga J. A.

González, A., Hernández, L., Perló, M., \& Zamora, I. (2010). Rescate de ríos urbanos: Propuestas conceptuales y metodológicas para la restauración y rehabilitación de ríos. Universidad Nacional Autónoma de México, Coordinación de Humanidades, Programa Universitario de Estudios Sobre la Ciudad. Recuperado de http://www.puec.unam.mx/pdf/publicaciones_digitales/rescate_rios_digital.pdf

Hernández-Fuentes, Y. (2010). Usos del agua en la ciudad de San Luis Potosí, 1831-1887 (Tesis de maestría). San Luis Potosí: Universidad Autónoma de San Luis Potosí, Programa Multidisciplinario de Posgrado en Ciencias Ambientales.

INEGI. (2010). Estudio hidrológico el Estado de San Luis Potosí. Aguascalientes, México: INEGI. Recuperado de http://internet.contenidos.inegi.org.mx/contenidos/productos/prod_serv/ contenidos/espanol/bvinegi/productos/historicos/2104/702825224097/702825224097.pdf

INEGI. (2011). Censo de población y vivienda 2010, principales resultados por localidad (ITER). Recuperado de http://www.inegi.org.mx/est/contenidos/proyectos/ccpv/cpv2010/iter_2010.aspx

INEGI. (2017). Red hidrográfica escala 1:50 000 edición 2.0, descarga en formato shape Subcuenca Hidrográfica RH37Gb -P. San José.

ITDP. (2017). Invertir para movernos, interactive map. Recuperado de: http://itdp.mx/ invertirparamovernos/\#!/mapa.

Jacobs, J. (1967). Muerte y vida de las grandes ciudades. Madrid: Ediciones Península.

La Corriente. (2016, agosto 12). Día de San Juan en San Luis. Revista la Corriente. Recuperado de http://revistalacorriente.com.mx/dia-de-san-juan-en-san-luis/

Lefebvre, H., Kofman, E., \& Lebas, E. (1996). Writings on cities, 63(2). Oxford: Blackwell.

Linton, J., \& Budds, J. (2014). The hydrosocial cycle: Defining and mobilizing a relational-dialectical approach to water. Geoforum, 57, 170-180. https://doi.org/10.1016/j.geoforum.2013.10.008

Lynch, K. (1960). The Image of the City. Boston: MIT Press.

Mehta, L., \& Karpouzoglou, T. (2015). Limits of policy and planning in peri-urban waterscapes: The case of Ghaziabad. Habitat International, 159-168. https://doi.org/10.1016/j. habitatint.2015.03.008

Mele, C. (2000). The materiality of urban discourse: rational planning in the restructuring of the early twentieth-century ghetto. Urban Affairs Review, 35(5), 628-648. https://doi. org/10.1177/10780870022184570

Mu-oz Pedreros, A. (2004). La evaluación del paisaje: Una herramienta de gestión ambiental. Revista chilena de historia natural, 77(1), 139-156. https://doi.org/10.4067/ S0716-078X2004000100011

\begin{tabular}{|c|c|c|}
\hline 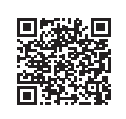 & (c) (1) (5) () & 68 \\
\hline
\end{tabular}




\section{Revista de CIENCIAS AMBIENTALES Tropical Journal of Environmental Sciences}

Revista de Ciencias Ambientales (Trop J Environ Sci). EISSN: 2215-3896. (Enero-Junio, 2019) . Vol 53(1): 45-69. D0l: http://dx.doi.org/10.15359/rca.53-1.3 Open Access: www.revistas.una.ac.cr/ambientales EMAlL: revista.ambientales@una.ac.cr López-Mares L. M., Lozano de Poo J. M., Torre-Silva F., Rodríguez-Santiago J. y López-Fraga J. A.

Padron, J. (2014). Los hombres del agua en San Luis Potosí, San Luis Potosí: INTERAPAS. Recuperado de http://www.interapas.mx/files/cultura_del_agua/publicaciones/Los_Hombres_ del_Agua.pdf

Perló, M., \& Zamora, I. (2017). Perspectivas ambientales sobre la contaminación y la recuperación del río Magdalena en la ciudad de México. Revista Internacional de Contaminación Ambiental, 33(3), 377-391. https://doi.org/10.20937/RICA.2017.33.03.02

Rogers, S., \& Crow-Miller, B. (2017). The politics of water: a review of hydropolitical frameworks and their application in China. Wiley Interdisciplinary Reviews: Water, 4(6), 1239. https://doi. org/10.1002/wat2.1239

Rojas, C., De Meulder, B., \& Shannon, K. (2015). Water urbanism in Bogotá. Exploring the potentials of an interplay between settlement patterns and water management. Habitat International, 48, 177-187. https://doi.org/10.1016/j.habitatint.2015.03.017

Salazar, G. (2010). Colonización y estructura del territorio. En Guadalupe Salazar (coorda.), Estudios del espacio arquitectónico y del territorio en San Luis Potosí (pp. 20-65). San Luis Potosí: Universidad Autónoma de San Luis Potosí.

Shannon, K. (2009). Water urbanism: hydrological infrastructure as an urban frame in Vietnam. In Feyen, J., Shannon, K., \& Neville, M. (Eds.). Water and urban development paradigms. Towards an integration of engineering, design and management approaches (pp. 55-66). London: CRC Press.

SIATL. (2018). Simulador de flujos de agua de cuencas hidrográficas. Recuperado de http:// antares.inegi.org.mx/analisis/red_hidro/siatl/\#

Swyngedouw, E. (1999). Modernity and hybridity: nature, regeneracionismo, and the production of the Spanish waterscape, 1890-1930. Annals of the Association of American Geographers, 89(3), 443-465. https://doi.org/10.1111/0004-5608.00157

Urquiola, J. I. (2004). Agua para los ingenios: San Luis Potosí y el valle de San Francisco a inicios de la época colonial. Estudio introductorio y documentos sobre ingenios de beneficio de metales. San Luis Potosí, San Luis: El Colegio de San Luis.

(c)

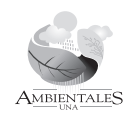

